DANIEL MANZONI DE ALMEIDA

ESTUDO DO POTENCIAL NEUTRALIZANTE DO SORO ANTIESFINGOMIELINASES D RECOMBINANTES, SOBRE AS AÇÕES TÓXICAS DOS VENENOS DAS ARANHAS LOXOSCELES

Dissertação apresentada ao Programa de Pós-Graduação em Imunologia do Instituto de Ciências Biológicas da Universidade de São Paulo, para obtenção do Título de Mestre em Ciências Biológicas (ênfase em Imunologia). 
DANIEL MANZONI DE ALMEIDA

\section{ESTUDO DO POTENCIAL NEUTRALIZANTE DO SORO ANTI- ESFINGOMIELINASES D RECOMBINANTES, SOBRE AS AÇÕES TÓXICAS DOS VENENOS DAS ARANHAS LOXOSCELES}

Dissertação apresentada ao Programa de PósGraduação em Imunologia do Instituto de

Ciências Biológicas da Universidade de São Paulo, para obtenção do Título de Mestre em Ciências Biológicas.

Área de Concentração:

Imunologia

São Paulo 2007 
ESTE TRABALHO FOI REALIZADO NO

LABORATÓRIO DE IMUNOQUÍMICA

DO INSTITUTO BUTANTAN
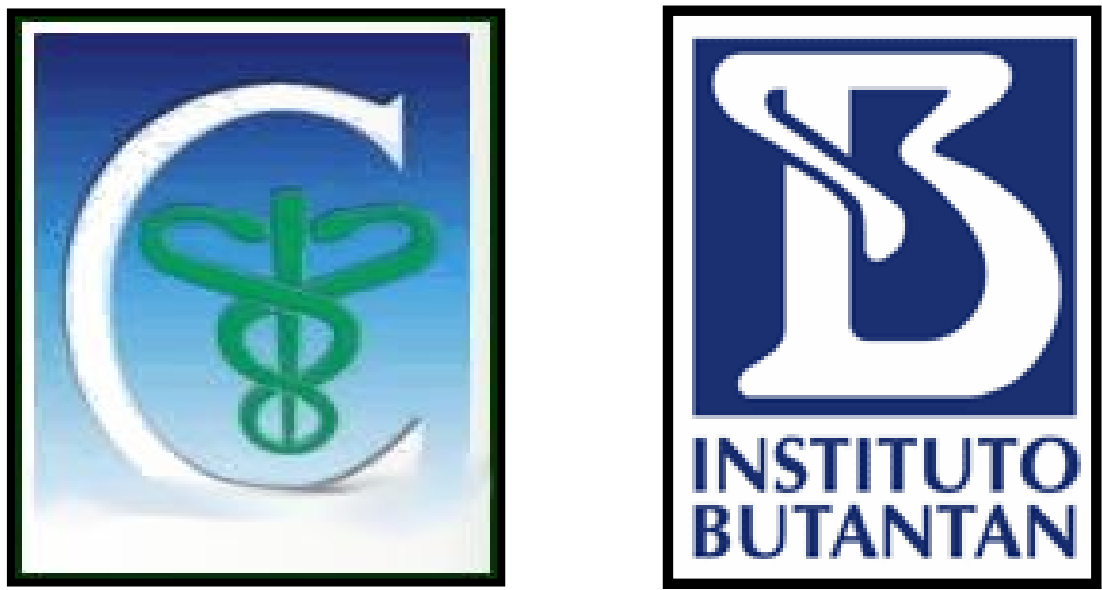

APOIO FINANCEIRO

FAPESP E CNPq 
Aos meus pais, Iraídes e Marli e meu irmão, Vinícius, por todo amor e apoio incondicional. 
Ao Fabrício Freire de Mello, pelo apoio, dedicação e carinho.

À Gabriela Rosa pelo incentivo e amizade. 


\section{AGRADECIMENTOS}

À minha orientadora, Profa. Dra. Denise Vilarinho Tambourgi, pela oportunidade de aprender ao seu lado, pela dedicação, pela formação profissional, pelos ensinamentos sérios, éticos e encantadores da ciência que permanecerão comigo por toda a minha carreira e pela amizade que levarei por toda a minha vida.

Aos meus pais, Iraídes e Marli e meu irmão, Vinícius, pelo amor, dedicação e incentivo em todos os momentos; à Gabriela Rosa pelo carinho e amizade; ao Fabrício Freire Melo pelo carinho, amizade, cumplicidade e companheirismo nesse nosso ano de teses e estradas.

À Dra. Rute Maria Gonçalves de Andrade pelos ensinamentos, respeito e dedicação e pela coleta, manutenção e extração dos venenos das aranhas Loxosceles.

Aos pesquisadores do Laboratório de Imunoquímica: Aparecida Santo Pietro, Fábio Carlos Magnoli, Jorge Mário da Costa Ferreira Jr., Mônica Spadafora Ferreira, Rute Maria Gonçalves de Andrade, Osvaldo Augusto Esteves Brazil Sant'Anna e Fernanda Calheta Vieira Portaro.

À equipe técnica do Laboratório de Imunoquímica pelo carinho que tiveram em todos os momentos: Helena Maria Machado, Elaine Rodrigues, Maura Coração, Sílvia Aparecida Camargo, Severino Ramos da Silva, João Batista Coelho, José Cassiano Borba, Gisélia Belmira Pereira e Márcia Franco. 
Aos atuais e ex-estudantes do Laboratório de Imunoquímica: Marta Ferreira Bastos, Giselle Pidde Queiroz, Alessandra Veloso de Melo, Cássia Regina Pichitelli, Gabriela Dicieri Tanaka, Isadora Maria Villas-Boas, Estevam José Baldom, Mara Adriana Corrêa, Karina Scaramuzzi, Eliana Blini Marengo, Luciana Vieira de Carvalho, Cinthya Kimori Okamoto, Lucas Ricardo Alves Pessoa, Guilherme de Santi-Ferrara Ibañez, Rosana de Fátima Shoji, Patrícia de Souza Santos, Matheus Fernandes-Pedrosa, Dra Danielle Paixão Cavalcante, Dra Kátia Cristina de Oliveira Lima, Mara Sílvia Carvalhaes, Joacir de Oliveira, Sônia Aparecida Andrade Chudzinski, Fernando Pretel, Matheus Ferracine e Carlos Felgueiras. Muito obrigado!

À Dra. Hisako Gondo Higashi e Dr. José Roberto Marcelino da Divisão Bioindustrial do Instituto Butantan pela importante colaboração ao desenvolvimento desse trabalho.

À Profa. Dra. Sonia Jancar Negro e Profa. Dra. Ises de Almeida Abrahamson pela supervisão e orientação junto ao Programa de Aperfeiçoamento de Ensino Superior. E, também, à turma animada e dedicada do curso de Farmácia e Bioquímica (BMI165:2006) pela oportunidade de aprendermos juntos.

À Dra. Celidéia Copi Vaz, Dra. Mônica Valdercy Lopes-Ferreira e Dra. Sandra Helena Poliselli Farsky pela participação na banca do exame de qualificação e contribuição ao presente estudo.

Às secretárias da Pós-Graduação do Departamento de Imunologia do ICB/USP, Jotelma Leite e Valéria, pelo apoio. 
À equipe do Biotério Central do Instituto Butantan e a Regina de Luca do Biotério do ICB/USP pelo suporte com os animais.

Aos amigos e amigas que fiz durante o período que estive no Instituto Butantan e ao longo da pós-graduação. Levarei nossa amizade para todo o sempre: Danielle Paixão Cavalcante, pela amizade singular que nem mesmo o Atlântico consegue separar diariamente; Elaine Rodrigues, pela amizade carinhosa e fraterna que levo comigo no coração; Ana Cláudia Rocha-Campos, pela amizade alegre e que também o Atlântico não consegue separar; Eliana Blini Marengo, pela amizade maravilhosa; Sônia Aparecida Andrade Chudzinski pelo apoio incondicional e por acreditar nos meus sonhos; Andréa Monteiro, pela amizade sincera; Ana Paula Azevedo, pela amizade determinada; Rogério Valois, pela amizade corajosa; Alessandra Veloso, pela amizade alegre e dedicada; Estevam Baldon, pela amizade sincera conquistada em pouco tempo; Lívia Melo, pela amizade leal e carinhosa; Carlos Lescovar, pela amizade conselheira; Alessandra Commodoro, pela amizade inspiradora; Ana Maria Rodrigues, pela amizade sensível.

Aos meus alunos Rosangela Madeiro, Fernanda Lima, Wesley de Almeida, Francisco de Lima Filho, Luís Nunes da Silva, Alda Ximenez, Regiane Madeiro e Michele Saboleski, pela confiança, parceria, amizade e contribuição à minha formação profissional.

À FAPESP e ao CNPq pelo incentivo e apoio financeiro. 
"Todo o nosso saber começa nos sentimentos"

(Leonardo da Vinci) 
MANZONI-DE-ALMEIDA D. - Estudo do potencial neutralizante do soro antiEsfingomielinases $\mathrm{D}$ recombinantes, sobre os efeitos tóxicos dos venenos das aranhas Loxosceles.

Os envenenamentos por aranhas do gênero Loxosceles (aranha-marrom), presente em regiões temperadas e tropicais das Américas, África e Europa, podem causar não somente dermonecrose, mas também sérios efeitos sistêmicos. Três diferentes espécies de Loxosceles são consideradas de importância médica no Brasil (L. laeta, L. intermedia, L. gaucho) e mais de 3.000 casos de envenenamento são reportados todos os anos. A terapia usada para o loxocelismo, no Brasil, é a administração do soro anti-Aracnídico, produzido pelo Instituto Butantan, pela imunização de cavalos com os venenos de Tityus serrulatus, Phoneutria nigriventer e Loxosceles gaucho. $O$ principal componente tóxico apresenta atividade de esfingomielinase $D(S M a s e ~ D)$ e várias isoformas dessa toxina estão presentes nos venenos de Loxosceles. Recentemente, foi produzido um novo soro anti-loxoscélico, pelo Laboratório de Imunoquímica juntamente com a Divisão Bioindustrial do Instituto Butantan, pela imunização de cavalos com as formas recombinantes das SMases D, i.e., duas isoformas de L. intermedia (SMases P1 e P2) e uma de L. laeta (SMase I). O objetivo do presente estudo foi comparar o potencial neutralizante do novo soro anti-SMases $D$ e do soro anti-Aracnídico contra os efeitos tóxicos dos venenos das aranhas do gênero Loxosceles, com importância médica no Brasil. A análise comparativa dos dois soros, por "Western blot", revelou que o anti-Aracnidico é capaz de reconhecer a maioria dos componentes presentes nos venenos de $L$. intermedia, L. laeta e L. gaucho. O anti-SMases D, em contraste, reconheceu somente os componentes de $30-35 \mathrm{kDa}$, massa molecular correspondente à das isoformas nativas de SMases $\mathrm{D}$ existentes nos venenos de Loxosceles. Por ELISA, foi mostrado que o soro anti-SMases D contém títulos superiores de lgGT, IgGa, b e c do que o anti-Aracnídico. Os testes de soroneutralização (in vivo and in vitro) mostraram que 0 soro anti-SMases $D$ tem melhor atividade inibitória do que 0 anti-Aracnídico, sobre as atividades tóxicas dos venenos de $L$. intermedia e $L$. laeta, como a dermonecrotica, hemolítica e esfingomielinásica. Para o veneno de L. gaucho, os resultados foram similares ou, em alguns casos, melhores usando o soro anti-Aracnídico. Em conjunto, os dados sugerem que, embora, o novo soro anti-SMases $\mathrm{D}$ apresente um significante potencial neutralizante, é ainda necessária a inclusão, na formulação de imunização, de uma isoforma de SMase $D$ do veneno de $L$. gaucho, para a obtenção de um antissoro capaz de neutralizar efetivamente os venenos das três principais espécies de aranhas Loxosceles que causam acidentes no Brasil. 


\section{ABSTRACT}

MANZONI-DE-ALMEIDA, D. Study of the neutralization potential of the antirecombinant Sphingomyelinases $D$ serum, on the toxic effects of Loxosceles spider venoms.

Envenomation by arachnids of the genus Loxosceles (brown spider), present in temperate and tropical regions of the Americas, Africa and Europe, can lead not only to local dermonecrosis but also to serious systemic effects. At least 3 different Loxosceles species of medical importance are known in Brazil, L. laeta, L. intermedia and L. gaucho, and more than 3000 cases of envenomation are reported each year. The used therapy for loxoscelism, in Brazil, is the administration of the anti-arachnidic serum, produced by Butantan Institute, by the immunization of horses with the venoms from Tityus serrulatus, Phoneutria nigriventer and Loxosceles gaucho. The main toxic component is endowed with sphingomyelinase D (SMase D) activity and various isoforms of this toxin are present in Loxosceles venoms. Recently, a new anti-loxoscelic serum was produced, by Immunochemistry Laboratory and the Production Division of Butantan Institute, by horse immunization with the recombinant form of the SMases D, i.e., two isoforms from L. intermedia (SMases P1 and P2) and one from L. laeta (SMase I). The aim of this study was to compare the neutralization potentials of the new anti-SMases $D$ and the anti-arachnidic sera, against the toxic effects of venoms from spiders of the Loxosceles genus of medical importance in Brazil. The comparative analysis of the two antisera, by Western blot, has revealed that the anti-arachnidic serum is able to recognize the majority of the components present on the venoms of $L$. intermedia, $L$. laeta e $L$. gaucho. The anti-SMases $D$, in contrast, has recognized only components of $30-35 \mathrm{kDa}$, which corresponds to the $\mathrm{Mr}$ of the natives SMases $\mathrm{D}$ isoforms present in the Loxosceles venoms. By ELISA, it has been determined that the anti-SMases $D$ serum contains higher titres of $\lg G T, \lg G a, b$ and $c$ than the anti-arachnidic serum. Serum neutralization tests (in vivo and in vitro) have showed that the anti-SMases $D$ serum has better inhibitory activity on the toxic activities of the venoms from $L$. intermedia and $L$. laeta, such as shingomyelinasic, dermonecrotic and haemolytic activites than the anti-arachnidic serum. For L. gaucho venom, the results have been similar or, in some cases, better by using the anti-arachnidic serum. These data suggest that, although the new anti-SMases $D$ serum shows a significant neutralization potential, it is still necessary the inclusion, in the immunization formulation, of a SMase D isoform from L. gaucho venom, in order to obtain a fully neutralizing antiserum against the three main important Loxosceles spiders that cause accidents in Brazil. 


\section{LISTA DE ABREVIATURAS}

\begin{tabular}{|c|c|}
\hline BCIP & 5-bromo-4-cloro-3-indolil-fosfato. \\
\hline BSA & albumina bovina sérica \\
\hline $\mathrm{cm}$ & centrímetros \\
\hline $\mathrm{cm}^{2}$ & centrímetros quadrados \\
\hline CD59 & "MIRL-mebrane inhibitor of reative lysis" \\
\hline CR1 & "Complement Receptor 1" \\
\hline $\mathrm{DAB}$ & "3,3 Diaminobenzidine tetrahydrochloride" \\
\hline DAF & "Decay accelerating factor" \\
\hline ELISA & "Enzyme-Liked Immunosorbent Assay" \\
\hline FITC & isotiocianato de fluoresceína \\
\hline FPLC & "Fast Perfomance Liquid Chromatography" \\
\hline g & grama \\
\hline GPC & glicoforina C \\
\hline $\mathrm{kDa}$ & quilodaltons \\
\hline $\mathrm{Kg}$ & quilograma \\
\hline $\mathrm{mA}$ & miliamper \\
\hline MCP & "Membrane Cofactor Protein" \\
\hline$\mu g$ & micrograma \\
\hline$\mu \mathrm{l}$ & microlitro \\
\hline $\mathrm{mg}$ & miligrama \\
\hline $\mathrm{mM}$ & milimolar \\
\hline$\mu \mathrm{M}$ & micromolar \\
\hline NBT & azul de nitrotetrazólio \\
\hline $\mathrm{nm}$ & nanômetro \\
\hline
\end{tabular}


OPD

PBS

rpm

SDS

SDS-PAGE

SHN

SMase D

TEMED

VBS $^{2+}$ ortofenil-diaminobenzidina

solução salina tamponada

rotações por minutos

dodecilsulfato de sódio

gel de poliacrilamida - dodecilsulfato de sódio

soro humano normal

Esfingomielinase D

$\mathrm{N}, \mathrm{N}, \mathrm{N}$ ", N" - Tetrametilenodiamina

Tampão veronal com íons 
SUMÁRIO

1 INTRODUÇÃO 4

1.1 A ARANHA MARROM: BIOLOGIA E OS PRINCIPAIS ASPECTOS CLÍNICOS DO ENVENENAMENTO

1.2 ESTUDOS BIOQUÍMICOS E IMUNOQUÍMICOS ....................................... 9

1.3 OS EFEITOS LOCAIS DO ENVENENAMENTO ….................................... 12

1.4 OS EFEITOS SISTÊMICOS OU VISCERAIS DO ENVENENAMENTO $\ldots \ldots . .15$

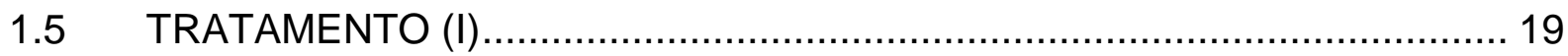

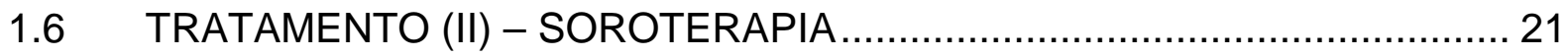

2 OBJETIVO

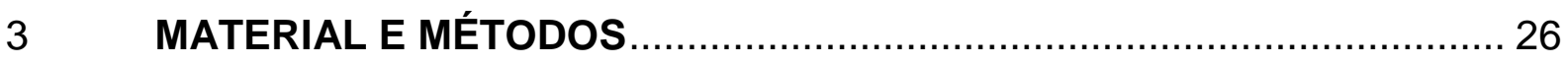

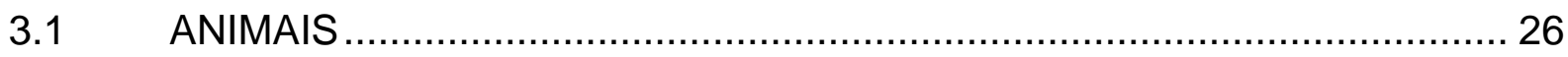

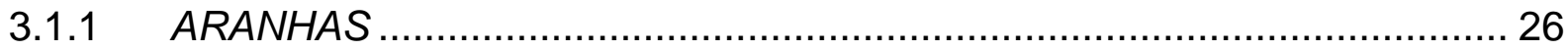

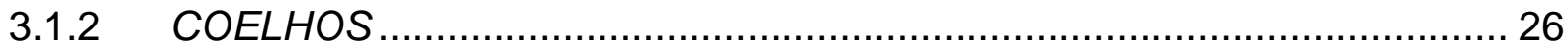

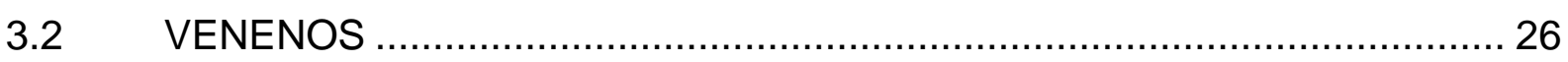

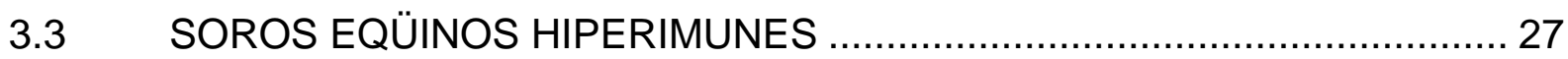

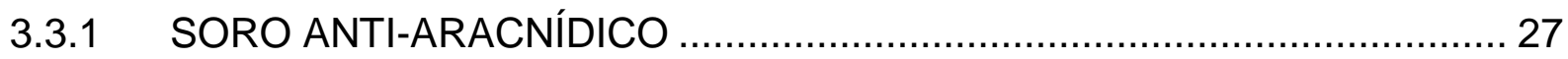

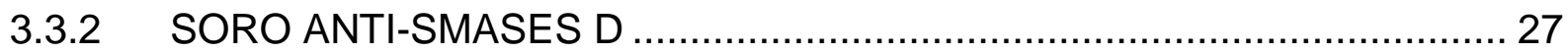

3.3.3 SORO ANTI-BOTRÓPICO ………………................................... 27

3.4 ANÁLISE DO RECONHECIMENTO DOS VENENOS PELOS SOROS ANTI-ARACNÍDICO E ANTI-SMASES D DE LOXOSCELES ….................. 28

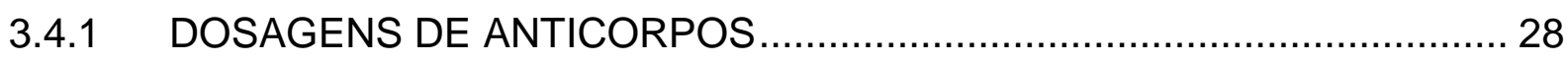

3.4.2 DETERMINAÇÃO DAS SUBCLASSES DE IgG PRESENTES NOS SOROS ANTI-ARACNÍDICO E ANTI-SMASES D .................................. 29

3.4.3 ANÁLISES QUALITATIVAS DOS SOROS ………............................... 29

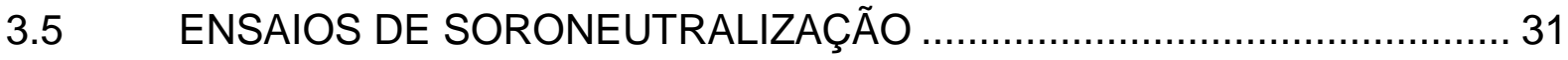

3.5.1 DETERMINAÇÃO DA ATIVIDADE DERMONECRÓTICA EM COELHOS 31

3.5.1.1 SORONEUTRALIZAÇÃO "IN-VIVO" 
3.5.1.2 SORONEUTRALIZAÇÃO "IN VTRO - IN VIVO".

3.5.2 DETERMINAÇÃO DA ATIVIDADE HEMOLÍTICA, DEPENDENTE DE COMPLEMENTO, INDUZIDA PELOS VENENOS DE LOXOSCELES ...... 32

3.5.2.1 SORO NORMAL HUMANO.............................................................. 32

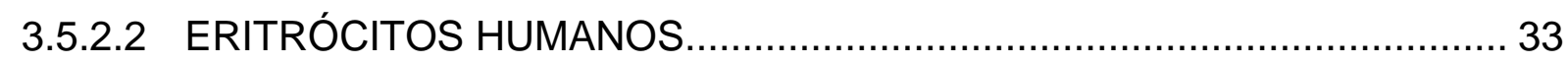

3.5.2.3 TRATAMENTOS DOS ERITRÓCITOS HUMANOS COM OS VENENOS DE

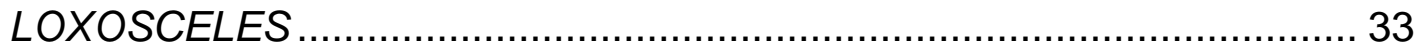

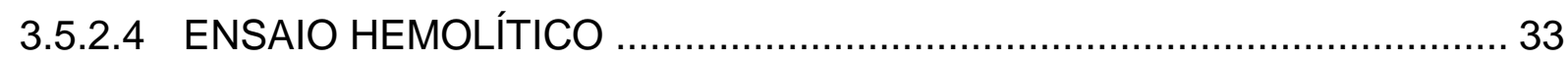

3.5.2.5 SORONEUTRALIZAÇÃO DA CAPACIDADE DE INDUÇÃO DA REMOÇÃO DE GLICOFORINA C DAS MEMBRANAS DE ERITRÓCITOS E DA LIGAÇÃO DAS TOXINAS À SUPERFÍCIE DAS CÉLULAS

3.5.3 DETERMINAÇÃO DA ATIVIDADE ESFINGOMIELINÁSICA DOS VENENOS DE LOXOSCELES.

3.5.3.1 DETERMINAÇÃO DA ATIVIDADE ESFINGOMIELINÁSICA RESIDUAL DAS AMOSTRAS DOS VENENOS DE LOXOSCELES. 35

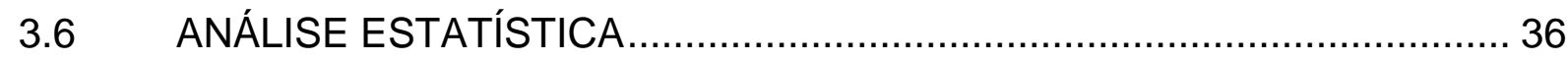

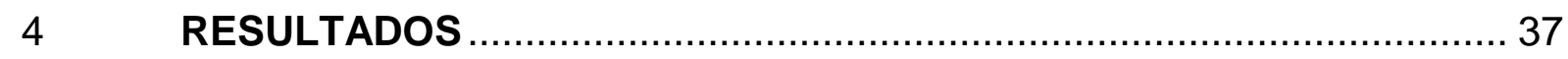

4.1 ANÁLISE DO RECONHECIMENTO DOS VENENOS PELOS SOROS ANTI-ARACNÍDICO E ANTI-SMASES D DE LOXOSCELES ….................. 37

4.1.1 por Western Blot.................................................................... 37

4.1.2 por ELISA - TÍTULOS DE ANTICORPOS ……………….................... 39

4.2 DETERMINAÇÃO DOS TÍTULOS DAS SUBCLASSES DE IgG DOS SOROS.

4.3.1 DA ATIVIDADE DERMONECRÓTICA …............................................... 42

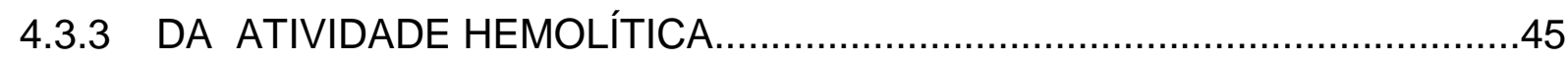

4.3.4 DA ATIVIDADE ESFINGOMIELINÁSICA D ............................................. 49

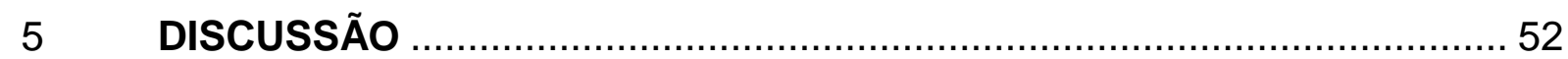

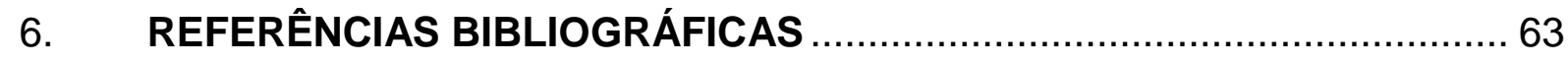




\section{INTRODUÇÃO}

\subsection{A ARANHA MARROM: BIOLOGIA E OS PRINCIPAIS ASPECTOS CLÍNICOS DO ENVENENAMENTO}

As aranhas estão classificadas no filo Arthropoda ordem Araneae, composta por aproximadamente 38.800 espécies catalogadas. A maioria das aranhas é peçonhenta (ANDERSON, 1982; RUSSEL, 1961) sendo característica nessas a presença de glândulas de veneno associadas às quelíceras. No entanto, segundo a Organização Mundial da Saúde, quatro gêneros são causadores de envenenamento em humanos (Araneísmo): Latrodectus, Phoneutria, Loxosceles e Atrax e, no Brasil, os três primeiros são de importância médica.

As aranhas do gênero Loxosceles, família Sicariidae, são conhecidas popularmente como aranhas marrons. São pequenas, de coloração geralmente marrom-avermelhada, possuem seis olhos dispostos em três díadas, pernas longas e finas. São de hábito noturno, preferem locais secos e constroem teia característica, de fios grosseiros e pegajosos (BUCHERL, 1969), podendo viver entre três a sete anos (GONÇALVES-DE-ANDRADE et al., 1999). O acidente humano, geralmente, ocorre por compressão da aranha contra o corpo.

As cem espécies descritas de Loxosceles apresentam ampla distribuição sendo encontradas em regiões temperadas e tropicais da América do Norte, Central e Sul e, também, na Europa e África (PLATNICK, 2005). Entre as espécies de Loxosceles existentes, destacam-se as que têm importância médica devido à incidência de acidentes a elas atribuídos, como é o caso, de Loxosceles spinuolosa

e Loxosceles parrami, espécies encontradas na África (NEWLANDS et al., 1982) e Loxosceles reclusa, nos Estados Unidos (FUTRELL, 1992). No Brasil há dez dessas 
espécies, sendo três de importância médica: Loxosceles gaucho, Loxosceles intermedia, Loxosceles laeta, que são encontradas nas regiões Sudeste e Sul (WASSERMAN et al., 1983; MINISTÉRIO DA SAÚDE, FUNDAÇÃO NACIONAL DA SAÚDE, 1998); Loxosceles intermedia é responsável por mais de 2000 casos de envenenamento na região Sudeste (FUNDAÇÃO NACIONAL DA SAÚDE, 1996).

As três espécies de Loxosceles de importância médica no Brasil diferem entre si, principalmente, pela coloração, características das pernas, e o lado dorsal do cefalotórax (FISCHER, 1994).

$\mathrm{Na}$ espécie Loxosceles intermedia (Figura 1), os machos possuem cefalotórax com linhas cefálicas não nítidas, pedipalpos longos, apresentando o último artículo ou tarso, saliente além da inserção do bulbo copulátório e estilete sinuoso. As fêmeas possuem cefalotórax com linhas cefálicas não tão nítidas, pedipalpo curto e simples, abdômen elíptico, na maioria das vezes superando o tamanho do cefalotórax e com pêlos abundantes e coloração esverdeada (FISCHER, 1994).

Em Loxosceles laeta (Figura 1), os machos apresentam cefalotórax pardoclaro, com a região cefálica de tonalidade mais escura, formando uma figura triangular e com margem posterior pontiaguda, devido às linhas cefálicas limitantes, estrias na região cefálica bastante nítidas, pedipalpo longo e estilete pontiagudo. As fêmeas diferem no cefalotórax com região cefálica de tonalidade pardaavermelhada, formando uma figura pentagonal devido às linhas cefálicas limitantes, com estrias longitudinais nítidas, pedipalpo fino e curto com as extremidades de tonalidades mais escuras; o abdômen, visto ventralmente, tem aspecto liso e uma região mais clara em forma de triângulo que vai desde a base até as fiandeiras (FISCHER, 1994). 
$\mathrm{Na}$ espécie Loxosceles gaucho (Figura 1), os machos possuem a região torácica com uma impressão mais clara, formada por bandas, porção anterior do cefalotórax formando na direção traseira um desenho em forma de " $\mathrm{v}$ ", apresentando pedipalpo com os últimos artículos proporcionalmente curtos e estilete curvado. As fêmeas apresentam região torácica com uma impressão mais clara formada por bandas, porção anterior do cefalotórax formando para trás um desenho em forma de "U" e pedipalpo com os últimos artículos proporcionalmente curtos e estilete curvado (FISCHER, 1994). 
q
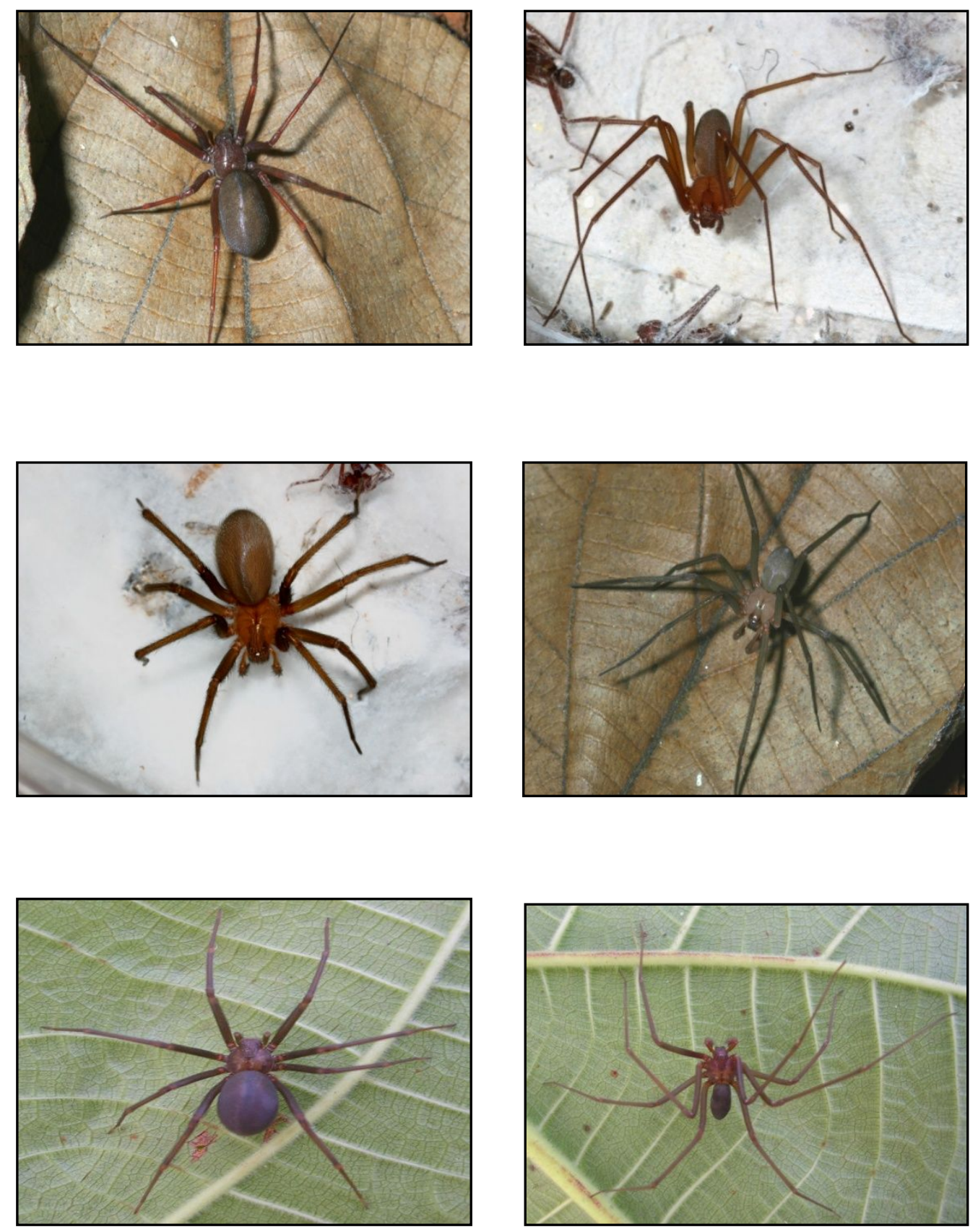

L. laeta

L. intermedi

L. gaucho

Figura 1: Aranhas Loxosceles de importância médica no Brasil. Fotos gentilmente cedidas por Rogério Bertani e Giuseppe Puorto - Instituto Butantan. 
Os acidentes causados por aranhas do gênero Loxosceles podem resultar em manifestações severas, especialmente necrose na pele, evoluindo para distúrbios hematológicos e renais, nas situações mais graves de envenenamento (FUTREL, 1992). A esse conjunto de sinais, associado a outros sintomas como febre, vômitos e náuseas, dá-se o nome de Loxoscelismo.

O loxoscelismo foi primeiramente descrito nos Estados Unidos, em 1872 (CAVENESS, 1872), seguido de muitos outros casos identificados em países como Chile, Peru, Argentina e Brasil. No Brasil, o primeiro caso reportado de acidente necrótico cutâneo, causado por veneno de aranha, foi em 1891, mas somente em 1954 tais acidentes foram relacionados com a aranha Loxosceles.

A maior parte dos casos de loxoscelismo (entre 84 a 97\%) caracteriza-se por um quadro de necrose no local da picada, sendo este denominado forma cutânea; entretanto, alguns casos (de 3 a 16\%) podem evoluir para a forma sistêmica ou visceral, na qual hemólise e coagulação intravascular podem ocorrer (Figura 2) (FUTREL, 1992; BEY, 1997).

$\mathrm{Na}$ maioria dos estudos clínicos, foi registrado que os sintomas se iniciam algumas horas após a picada e aumentam com 24-72 horas, momento em que os pacientes procuram 0 atendimento médico. Os acidentados apresentam, principalmente, dor no local da picada, edema com endurecimento, eritema, equimose e isquemia, podendo ou não evoluir para necrose tecidual e úlcera. Nos casos que evoluem para a forma sistêmica, os pacientes podem apresentar hemólise, coagulação intravascular, trombocitopenia, hematúria, hemaglobinúria, rabdomiólise, choque e falência renal aguda (FUTREL, 1992; PAULI et al., 2006).

Outros sintomas como náuseas, vômitos, diarréia, sudorese, prurido, astenia, visão turva, febre, irritabilidade e distúrbios de consciência, foram observados em 
aproximadamente $50 \%$ dos pacientes com loxoscelismo cutâneo e em grande parte dos com loxoscelismo sistêmico (FUTREL, 1992; PAULI et al., 2006).

A

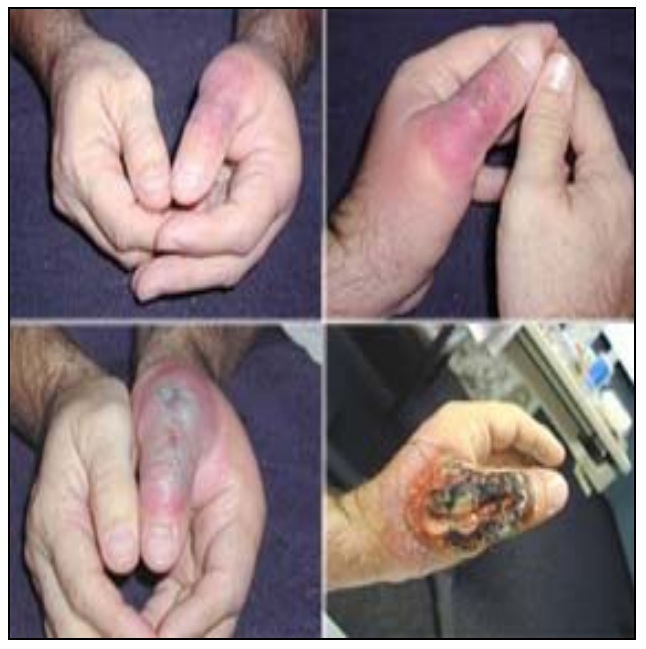

B

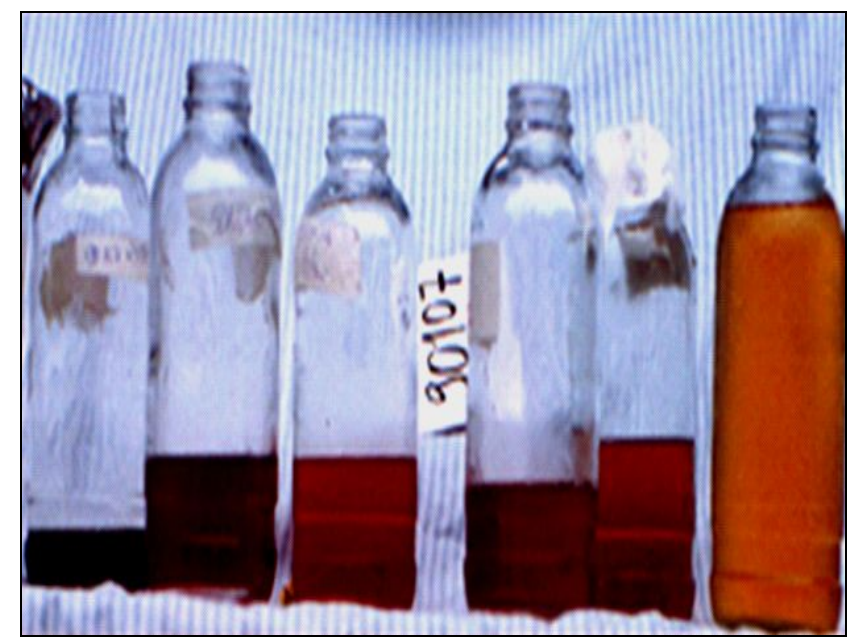

Figura 2: (A) Loxoscelismo cutâneo: Lesão dermonecrótica caracterizada por edema, inflamação e necrose. (B) Loxoscelismo sistêmico: detalhe da urina de paciente com hemoglubinúria.

\subsection{ESTUDOS BIOQUÍMICOS E IMUNOQUÍMICOS}

A severidade dos acidentes por aranhas Loxosceles parece estar associada à espécie, sexo, estágio de desenvolvimento da aranha, quantidade de veneno inoculada e das características genéticas e nutricionais do indivíduo acidentado (MINISTÉRIO DA SAÚDE, FUNDAÇÃO NACIONAL DA SAÚDE, 1998; DE OLIVEIRA et al., 1999; GONÇALVES-DE-ANDRADE et al., 1999; SEZERINO et al., 1998; TAMBOURGl et al., 1998; PRETEL et al., 2005). DE OLIVEIRA et al. (2005) analisando comparativamente, por eletroforese, as peçonhas de ambos os sexos de L. intermedia e L. laeta, verificaram a ocorrência de variações intra- e interespecíficas na composição de proteínas desses venenos. Este estudo 
demonstrou, também, que os venenos das fêmeas são mais tóxicos do que os dos machos e que os das fêmeas de L. laeta são os mais nocivos.

Os venenos das aranhas Loxosceles possuem uma composição complexa de toxinas e essas estão associadas aos seus efeitos deletérios (NORMENT et al., 1979).

Nas diferentes espécies de Loxosceles a presença da esfingomielinase D (32-35 kDa) tem sido responsabilizada pela necrose, hemólise e trombocitopenia (FORRESTER et al., 1978; KURPIEWSKI, 1981; TAMBOURGI et al., 1998). Outras enzimas, como a hialuronidase (FUTRELL, 1992; WRIGHT, 1973), algumas proteases (VEIGA, 2000; VEIGA et al., 2001a; VEIGA et al., 2001b), dentre as quais as metaloproteinases (YONG et al., 2001), parecem contribuir, tanto para o estabelecimento da lesão, como também para os efeitos sistêmicos nocivos do veneno (JONG et al., 1979; VEIGA, 2000).

TAMBOURGI et al. $(1995,1998)$ identificaram e caracterizaram as toxinas de L. intermedia responsáveis pelos efeitos locais e sistêmicos induzidos pelo veneno. Esses componentes, com massa molecular (Mr) de $35 \mathrm{kDa}$, foram purificados por gel filtração e denominados de Fração 35 (F35) (TAMBOURGl et al., 1998a; TAMBOURGI et al., 1995). Essa fração é responsável pelas ações dermonecrótica e hemolítica, sendo a última dependente, principalmente, da ativação da via alternativa do complemento (TAMBOURGI et al., 1995); quando injetada em camundongos induziu a produção de mediadores inflamatórios, tais como: Fator de Necrose Tumoral (TNF), as interleucinas IL-6 e IL-10 e óxido nítrico (TAMBOURGI et al., 1998b). Ao submeter a F35 à cromatografia de fase reversa foram obtidos três picos contíguos, denominados P1, P2 e P3. A análise em SDS-PAGE revelou que P1 e P2 continham uma única banda, e P3 duas bandas, com massa molecular aproximadamente de $35 \mathrm{kDa}$. A caracterização funcional de P1 e P2 revelou a 
presença de atividade esfingomielinásica e que cada proteína induzia, in vivo, os mesmos efeitos locais e sistêmicos do veneno bruto de Loxosceles. Em todos os ensaios P2 foi mais ativa que P1 e P3 caracterizada como uma isoforma inativa (TAMBOURGI et al., 1998a).

Fernandes Pedrosa et al. (2002) clonaram e expressaram, funcionalmente, uma toxina de aproximadamente $32 \mathrm{kDa}$ do veneno de L. laeta, que foi denominada esfingomielinase I (SMase I). Essa proteína é dotada de todas as atividades tóxicas descritas para o veneno total de Loxosceles. Recentemente, as SMases P1 e P2 de L. intermedia também foram clonadas e as proteínas recombinantes foram capazes de reproduzir todos os efeitos biológicos do veneno total e das toxinas P1 e P2 nativas (TAMBOURGI et al., 2004).

Estudos sobre a estrutura secundária das SMases P1, P2 e SMase I mostraram que essas são ricas em $\alpha$-hélices, importantes para sua atividade (DE ANDRADE et al., 2005). Outros estudos estruturais demonstraram que o sítio catalítico das SMases $\mathrm{D}$, envolvido na hidrólise de esfingomielina, possui uma região de ligação para o íon $\mathrm{Mg}^{2+}$ e dois resíduos de histidina, formando um sistema catalítico via ácido-base, uma característica geral de SMases neutras (MURAKAMI et al., 2005). 


\subsection{OS EFEITOS LOCAIS DO ENVENENAMENTO}

A lesão dermonecrótica foi descrita pela primeira vez, em 1872, por Caveness e Schmaus, em 1929, sugeriu que a lesão poderia estar ligada à picada da aranha $L$. reclusa. Em 1947, Machiavello fez associação entre o envenenamento por L. laeta com a ferida gangrenosa do Chile, mas foi em 1957 e depois em 1958 que ATKINS e colaboradores descreveram que as aranhas L. reclusa eram as responsáveis pelo araneísmo necrótico.

A principal manifestação do envenenamento por Loxosceles é a dermonecrose, ou seja, pelo desenvolvimento de necrose do tecido local atingido pelo veneno. A patogênese desta reação ainda não é totalmente conhecida, embora possa ser induzida em coelhos e cobaios (ATKINS et al., 1958; MORGAN, 1969; FUTRELL, 1992).

O desenvolvimento da lesão se inicia com o aparecimento de edema, nas primeiras 3 horas após o envenenamento, progride para níveis máximos em 24 horas com hemorragia cutânea e a seguir para uma lesão necrosada.

Análises histopatológicas da pele de coelhos, inoculados com veneno de Loxosceles, mostraram alterações que incluíam edema, espessamento do endotélio e degeneração das paredes dos vasos sanguíneos, compilação de células inflamatórias, vasodilatação, coagulação intravascular, hemorragia subcutânea e intradérmica. O acúmulo de leucócitos polimorfonucleares (PMN) é bem pronunciado e a formação de abscesso e necrose podem ocorrer em 3 a 5 dias. $O$ acúmulo de leucócitos e eritrócitos ao redor das vênulas pode ser observado 3 horas após o envenenamento, sugerindo perda de integridade vascular (FUTREL, 1992).

A reação dermonecrótica, induzida pelo veneno de Loxosceles, assemelha-se àquela observada nas reações de Arthus e Shwartzman, nas quais está bem 
documentada a participação do sistema do complemento e de leucócitos (SMITH e MICKS, 1970; BUTZ et al., 1971). Smith e Micks (1970) mostraram que o sistema complemento e o acúmulo de PMN no local são necessários para a formação da lesão, uma vez que esta não foi observada nos animais em que leucopenia ou depleção de sistema complemento foi induzida, sugerindo a participação de mediadores inflamatórios no desenvolvimento da dermonecrose nos envenenamentos por Loxosceles.

Alguns estudos têm sido realizados para determinar quais mediadores inflamatórios poderiam estar envolvidos no recrutamento de PMN para o local da lesão. Patel et al. (1994) verificaram que o veneno de Loxosceles reclusa é um ativador potente de células endoteliais, promovendo a indução da expressão de E-selectina e aumentando a expressão de IL-8 e GM-CSF, estimulando assim a migração de neutrófilos e a maturação de granulócitos/macrófagos, respectivamente; entretanto, esse veneno não promoveu a expressão da molécula de adesão ICAM-1 ou de IL-6. Outro estudo mostrou que a incubação do veneno de L. deserta com células endoteliais ou epiteliais causa aumento dos níveis de IL-8 e GRO- $\alpha$ (growth-regulated oncogene a) e MCP-1 (DESAI, 2000). Além disso, esse veneno é um potente indutor da expressão do fator de crescimento endotelial vascular (VEGF), em queratinócitos humanos, o qual pode estar envolvido na angiogênese e no aumento da permeabilidade vascular, com conseqüente vasodilatação, formação de edema e eritema. Málaque et al. (1999) detectaram em culturas primárias de queratinócitos humanos, após incubação com veneno de $L$. gaucho, altos níveis de TNF-a, outro ativador de células endoteliais, potencializando o quadro inflamatório.

Alguns trabalhos foram realizados na tentativa de identificar os principais componentes do veneno das aranhas Loxosceles que estariam envolvidos na 
indução de dermonecrose. Componentes, com massas moleculares relativas (Mr) entre 30 e $37 \mathrm{kDa}$, foram associados às ações dermonecrótica e letal. Proteínas com Mr de 34 kDa presentes nos venenos de L. reclusa (MORGAN, 1969), de 33 - 35 kDa de L. gaucho (BÁRBARO et al., 1992) e de 35 kDA de L. intermedia (TAMBOURGl et al., 1995) foram associadas às ações locais e sistêmicas em modelos experimentais.

Avaliando os mecanismos moleculares envolvidos na gênese do loxoscelismo cutâneo, Tambourgi et al. (2005) mostraram que as SMases D dos venenos de Loxosceles são capazes de induzir dermonecrose dependente da ativação de complemento em animais inoculados com veneno ou suas SMases D nativas ou recombinantes e, em conseqüência, uma infiltração maciça de neutrófilos no local da injúria. O infiltrado de neutrófilos diminuiu em animais descomplementados, pelo tratamento com cobra venom factor (CoVF), ou em C6-deficientes, sugerindo que fatores derivados da ativação da cascata do sistema do complemento, particularmente C5a e MAC (Complexo de Ataque à Membrana), estão envolvidos no desenvolvimento da dermonecrose. Entretanto, outras injúrias como hemorragia e dissociação de fibras colágenas não foram prevenidas nesses modelos. Posteriormente, em análises por zimografia de extratos de peles, foi mostrada a expressão de gelatinases endógenas, como a MMP-9, em grandes concentrações, nos animais inoculados com venenos ou suas SMases D. A expressão de MMP-9 e de outra gelatinase endógena, a MMP-2, foi também observada em culturas de fibroblastos incubadas com veneno e SMases de Loxosceles, sugerindo, assim, a participação dessas proteases no quadro dermonecrótico.

Em continuação a esse estudo, Paixão-Cavalcante et al. (2006) mostraram que, em culturas de queratinócitos humanos, o veneno de Loxosceles intermedia e as SMases D têm a capacidade de induzir apoptose, e que este fenômeno estava 
associado ao aumento das gelatinases MMP-2 e MMP-9 (PAIXÃO-CAVALCANTE et al., 2006). Paixão-Cavalcante et al. (2007) mostraram, ainda, em culturas de fibroblastos humanos e de coelhos, que a viabilidade era também comprometida, de forma dose dependente da concentração do veneno de $L$. intermedia, e que a mortalidade era inibida pela adição do inibidor de metaloproteases, a tetraciclina. 0 mesmo foi observado in vivo quando a tetraciclina foi usada no tratamento de lesões de coelhos inoculados com veneno de $L$. intermedia, sugerindo o potencial terapêutico da tetracilina no tratamento do loxoscelismo cutâneo.

\subsection{OS EFEITOS SISTÊMICOS OU VISCERAIS DO ENVENENAMENTO}

No quadro sistêmico do envenenamento por Loxosceles as principais manisfestações observadas são: distúrbios hematológicos, como anemia hemolítica e coagulação intravascular disseminada, e comprometimento renal, observado em $16 \%$ dos casos de acidente por Loxosceles, sendo tais alterações implicadas, direta ou indiretamente, na maioria das mortes (FUTREL, 1992).

Para os estudos dos efeitos sistêmicos do veneno de Loxosceles, Morgan et al., (1979) desenvolveram um método in vitro para o estudo da hemólise associada ao veneno de L. reclusa. Por meio deste, observaram que os eritrócitos humanos, incubados com veneno de L. reclusa, eram lisados quando incubados com soro humano fresco (grupo sanguíneo compatível), mas não pelo mesmo soro inativado por aquecimento. Os eritrócitos não tratados com veneno não eram lisados. Esses resultados sugeriam a participação do sistema do complemento no fenômeno da lise de hemácias humanas no envenenamento por Loxosceles.

Em continuação a esses estudos, Tambourgil et al. (1995) mostraram que hemácias humanas pré-tratadas com os venenos das aranhas do gênero Loxosceles 
de importância médica no Brasil, L. gaucho, L. intermedia ou L. laeta, ou com a fração F35, purificada do veneno de Loxosceles intermedia, tornavam-se susceptíveis a ação lítica do sistema do complemento. Em análises por citometria de fluxo revelaram que a lise dos eritrócitos era predominantemente ocasionada pela ativação e deposição de componentes da via alternativa do sistema do complemento. Entretanto, observou-se que componentes atuantes na via clássica, como $\mathrm{C} 1, \mathrm{C} 2$ e C4, também, encontravam-se depositados na superfície dessas células tratadas com os venenos e incubadas com soro humano normal autólogo. Investigando a participação da via clássica do sistema do complemento, Tambourgi et al. $(2002,2007)$ mostraram que a ativação da via clássica era causada pela ligação direta de C1q à membrana dos eritrócitos tratados com as SMases D de Loxosceles

As células nucleadas e eritrócitos são resistentes à morte mediada por complemento autólogo através de vários mecanismos conhecidos, incluindo a presença de fatores reguladores da vias alternativa e clássica, presentes na membrana, como MCP, DAF, CR1 e CD59. A remoção, bloqueio, alterações funcionais ou estruturais destes reguladores pode privar as células de seus mecanismos naturais de proteção contra os efeitos da ativação espontânea do complemento. Ensaios por citometria de fluxo não revelaram nenhuma alteração significativa na expressão desses reguladores de superfície de hemácias tratadas com veneno e/ou toxina purificada de Loxosceles. No entanto, tais estudos permitiram demonstrar que as SMases são capazes de se ligar à superfície dessas células (TAMBOURGI et al., 1995, 2000).

A falha de controle da ativação do sistema do complemento autólogo, induzida pelo veneno de Loxosceles, não é devida à remoção ou bloqueio funcional das moléculas regulatórias do sistema do complemento, mas sim a uma outra 
modificação nos eritrócitos que promove a falha da regulação. A superfície de hemácias humanas abriga resíduos de ácido siálico que estão, principalmente, associados às moléculas de glicoforinas, cuja ação inibitória do sistema do complemento foi reportada (TANNER, 1993; OKADA et al. 1982; BRAUCH et al., 1983).

Tambourgi et al. (2000) mostraram, através de ensaios de citometria de fluxo que o veneno de L. intermedia e suas SMases D purificadas, quando incubados com eritrócitos humanos, têm a capacidade de induzir clivagem das glicoforinas $A, B$ e $C$ da membrana dessas células. Por ensaios de "Western Blotting" foi verificado que tanto o veneno quanto as SMases D não apresentavam qualquer atividade proteolítica direta sobre a glicoforina purificada. Esses dados sugeriram que a clivagem das glicoforinas da membrana dos eritrócitos humanos tratados com veneno ou SMases D de Loxosceles ocorre de forma indireta, pela indução da ativação de uma metaloproteinase endógena, uma vez que o uso de quelantes de íons bivalentes, como o EDTA, e do inibidor de metaloproteinase, a 1,10fenantrolina, inibiu a remoção dessas moléculas da superfície dos eritrócitos.

Outros efeitos sistêmicos podem ser observados nos quadros de envenenamento por Loxosceles. Análises laboratoriais e clínicas, realizadas em alguns pacientes acidentados com aranhas do gênero Loxosceles, revelaram um quadro de hemoglobinúria, hematúria e proteinúria devido aos distúrbios hematológicos induzidos pelo veneno e, como conseqüência, danos renais agudos (FUTREL, 1992). Tambourgi et al. (1998) mostraram, após o envenenamento por $L$. intermedia, em análises histológicas de rins de camundongos, alterações como necrose tubular aguda, alterações nos néfrons, acompanhadas de deposição de material eosinófilico nos túbulos distal e proximal, sugerindo que os danos renais são ocasionados de forma indireta pela deposição de produtos dos efeitos 
sistêmicos. Luciano et al. (2004) observaram a ligação direta de componentes do veneno de L. intermedia a estruturas renais, sugerindo que esses componentes induzem a nefrotoxicidade observada no envenenamento.

Nos envenenamentos por Loxosceles pode também ocorrer alterações no sistema da coagulação sanguínea, como prolongamento do tempo de coagulação, coagulação intravascular e trombocitopenia. Essas alterações foram reportadas, pela primeira vez, em relação a ação do veneno de $L$. reclusa e da fração contendo esfingomielinase $D$, tendo sido sugerido o envolvimento da agregação plaquetária no mecanismo de dermonecrose (KURPIEWSKI, 1981).

Uma das conseqüências patológicas da agregação plaquetária é a oclusão das veias. A agregação plaquetária foi observada tanto em humanos quanto em coelhos envenenados por Loxosceles (FUTRELL, 1992). DA SILVA et al. (2003) correlacionando os dados de estudos hematológicos com os histopatológicos, de coelhos inoculados com o veneno de L. intermedia, detectaram um quadro de trombocitopenia e neutropenia e consideraram que este seria um efeito transitório do envenenamento e decorrente de uma intensa migração de plaquetas e neutrófilos para o local da lesão. TAVARES et al. (2004) mostraram a ação do veneno de L. gaucho sobre o sistema hemostático de coelhos. Os dados obtidos revelaram elevação dos fatores da coagulação V, VII, VIII, IX, XI e fibrinogênio, leucopenia e trombocitopenia, alterações que podem contribuir para o desenvolvimento da lesão local.

van den Berg et al. (2007) investigaram a ação do veneno de L. intermedia e suas SMases D sobre receptores de membrana das células endoteliais, envolvidos na interação com a trombina e Proteína C, a Trombomodulina e o Receptor Endotelial de Proteína C (EPCR), respectivamente. Nesse estudo, os autores mostraram que o veneno de $L$. intermedia e as SMases D induzem ativação de 
metaloproteases endógenas que clivam esses receptores de membrana, tendo como conseqüência a redução na capacidade de geração de Proteína $C$ ativada, importante mecanismo fisiológico de anticoagulação. Tal evento pode participar na gênese da coagulação intravascular presente nas formas graves de loxoscelismo sistêmico.

\subsection{TRATAMENTO (I)}

Diferentes intervenções e medicamentos têm sido propostos para o tratamento dos casos de envenenamentos por Loxosceles, tais como: remoção cirúrgica do tecido afetado, analgésicos, vasodilatadores, anti-histamínicos, antibióticos, corticóides, dapsona e antivenenos. Apesar do uso desses tratamentos, estudos sobre a eficiência dos mesmos não foram ainda muito conclusivos (PAULI et al., 2006).

A intervenção cirúrgica é utilizada para remoção da lesão no local da picada e é realizada em vários países, de acordo com a experiência regional e característica do envenenamento. Essa forma de tratamento é recomendada apenas para a reconstrução plástica em casos de permanência da lesão tecidual necrosada (WENDEL, 2003; BARBARO e CARDOSO, 2003; HOGAN et al., 2004; DA SILVA et al., 2003). No entanto, tal procedimento pode aumentar a inflamação local, exacerbar os efeitos do veneno, prolongar a injúria tecidual, aumentar a extensão da lesão e, conseqüentemente, contribuir para a rejeição de implantes de tecidos futuros e formação de ulceração crônica (KING, 1985; REES et al., 1985; FUTREL, 1992; SHIP, 1998; WENDEL, 2003; DA SILVA et al., 2004).

O uso de antibióticos no tratamento do envenenamento por Loxosceles é comum nos Estados Unidos. Tal forma de tratamento é utilizada na tentativa de 
prevenir infecções secundárias no local da picada (HOGAN et al., 2004), mas em outros países, o uso destes é considerado inadequado, uma vez que foi demonstrado que infecções secundárias não são muito comuns nesses acidentes (SEZERINO et al., 1998; SCHENONE, 2003; BÁRBARO e CARDOSO, 2003).

Corticóides são utilizados no tratamento do loxoscelismo em muitos países, inclusive no Brasil. Esses compostos são administrados em casos graves, especialmente em crianças, pois se acredita que possam ajudar a prevenir a hemólise e a falência renal, quando aplicados logo nas primeiras horas do envenenamento (REES et al., 1981; SMITH e BALDWIN, 1998; FUTREL, 1992; GOMEZ et al., 1999). Entretanto, foi constatado que o uso de corticóide não inativa o veneno ou inibe os seus efeitos primários, não prevenindo, assim, o aparecimento da necrose (PAULI et al., 2006).

A Dapsona é um medicamento usado no tratamento da lepra e nos últimos tempos tem sido recomendada para os casos de envenenamento por Loxosceles. Os resultados do uso da Dapsona no tratamento de loxoscelismo mostraram que o seu efeito se dá pela inibição da migração e infiltração de neutrófilos no foco inflamatório da lesão, retardando assim a injúria tecidual mediada pela ação dessas células. Entretanto, o uso da Dapsona não é indicado em casos de loxoscelismo sistêmico e alguns autores questionam sua eficiência, pois há falta de estudos mais aprofundados sobre sua ação após muitas horas do acidente (PAULI et al., 2006).

A soroterapia é o tratamento mais utilizado para os casos de envenenamento por Loxosceles, principalmente no Brasil. Esse tratamento é proposto para a neutralização das toxinas circulantes dos venenos, por moléculas heterólogas e específicas, os anticorpos. Acredita-se que essa terapia reduza os riscos de desenvolvimento do quadro sistêmico, como hemólise, coagulação intravascular disseminada, falência renal e possíveis complicações fatais (PAULI et al., 2006). 


\subsection{TRATAMENTO (II) - SOROTERAPIA}

Um dos principais objetivos no estudo de toxinas animais é a busca de uma terapia adequada para os envenenamentos causados por animais peçonhentos. Assim, desde o final do século XIX foi iniciado, por vários grupos de pesquisa, o estudo e o desenvolvimento da soroterapia para acidentes, principalmente os ofídicos. Desses estudos, destaca-se o de Calmette, em 1894, que mostrou pela primeira vez as propriedades terapêuticas da utilização de soros de cavalos imunizados, sobre os efeitos deletérios da ação dos venenos. No Brasil, tais estudos foram iniciados por VITAL BRAZIL, que mostrou que o soro anti-Naja produzido por CALMETTE era ineficiente em neutralizar os efeitos tóxicos dos venenos das serpentes brasileiras. Posteriormente, foram produzidos soros através da imunização de cavalos com venenos de serpentes brasileiras e foi Vital Brazil o primeiro a defender a idéia da especificidade de ação dos soros para utilização na terapia.

A técnica utilizada para a produção de soros consiste na utilização de animais de grande porte, como cavalos, que são imunizados com venenos de uma ou mais espécies de animais peçonhentos de importância médica; após uma série de ciclos de imunização esses animais são sangrados e os soros obtidos. Os soros contendo anticorpos com capacidade neutralizante para as toxinas dos venenos são classificados como mono- ou poliespecíficos, mas também referidos como mono ou polivalentes, ou seja, se são produzidos apenas contra um veneno ou toxina de uma espécie de animal ou contra uma mistura de venenos ou toxinas animais, respectivamente (BRAZIL, 1905). Atualmente, a soroterapia é considerada o 
tratamento mais eficiente para reverter os efeitos tóxicos causados pelos venenos animais.

Os principais grupos de animais peçonhentos com importância médica, cujos acidentes são passiveis de tratamento por soroterapia, incluem serpentes, escorpiões, aranhas, lagartas e animais marinhos. No Brasil, o Ministério da Saúde compra a produção dos soros de diversas instituições públicas como: o Instituto Butantan, em São Paulo, Instituto Vital Brazil, no Rio de Janeiro, Fundação Ezequiel Dias, em Belo Horizonte e o Centro de Produção e Pesquisa em Imunobiológicos, em Curitiba, e os distribuí para hospitais de todo o país por meio da Fundação Nacional de Saúde do Ministério da Saúde. Eventualmente, os soros antivenenos produzidos no Brasil são utilizados para suprir a carência de outros países da América Latina.

No Brasil o tratamento soroterápico, para os acidentes causados por aranhas do gênero Loxosceles, é realizado pela administração do soro anti-Aracnídico, produzido pela imunização de cavalos com os venenos de L. gaucho, Tityus serrulatus e Phoneutria nigriventer ou pelo soro anti-Loxosceles, produzido pela imunização de cavalos com os venenos de L. gaucho, L. intermedia e L. laeta.

Diversos estudos sobre o potencial neutralizante de soros anti-Loxosceles foram conduzidos ao longo dos anos, na tentativa de se obter um soro mais eficiente para o tratamento humano. Nos Estados Unidos, Ress et al. (1981) mostraram que a atividade dermonecrótica, induzida pelo veneno de Loxosceles reclusa, foi neutralizada com o uso do soro específico, inoculado diretamente no local da lesão. No Brasil, BÁRBARO et al. (1994) verificaram a reatividade cruzada do soro antiAracnídico e de um soro experimental anti-Loxosceles (produzidos em coelhos) com os venenos das espécies de importância médica. Bárbaro et al. (1996) demonstraram que os anticorpos encontrados no soro de coelhos e cavalos, contra 
toxinas das peçonhas de L. gaucho, L. laeta e L. intermedia, eram capazes de reconhecer com diferentes intensidades os três venenos, sugerindo uma conservação de determinantes antigênicos comuns.

Braz et al. (1999) e Bárbaro et al. (2005) analisando comparativamente, o potencial neutralizante de soros eqüinos anti-L. intermedia, produzido no Centro de Pesquisa Produção de Imunobiológico do Paraná, e anti-Aracnídico, produzido no Instituto Butantan, mostraram que o primeiro era o mais eficiente na neutralização da ação letal do veneno em modelo murino. Bárbaro et al. (2005), ainda, mostraram que esses dois soros apresentam a mesma eficiência na neutralização das demais atividades tóxicas dos venenos de importância médica no Brasil e a reatividade cruzada para o veneno de $L$. reclusa. Analisando a reatividade e neutralização dos venenos das espécies de importância médica na América, De Roodt et al., (2007) mostraram que os soros experimentais anti-Loxosceles boneti e anti-Loxosceles reclusa apresentam reatividade cruzada entre si e com os venenos de L. gaucho e L. laeta e que ainda foram capazes de neutralizar a dermonecrose a letalidade em camundongos.

Guilherme et al. (2001) demonstraram in vivo que o anticorpo monoclonal MoALg1, produzido contra o componente de $35 \mathrm{kDa}$ indutor da dermonecrose de L. gaucho, foi capaz de reduzir a lesão dermonecrótica em 90-97\% após seis horas do envenenamento. Entretanto, esse anticorpo não neutralizou com eficiência a dermonecrose induzida pelos venenos de L. laeta e $L$. intermedia. Esses resultados sugerem a existência de epítopos diferentes nos componentes dermonecróticos dos venenos das três espécies. Um soro policlonal experimental anti-L. gaucho produziu uma redução significante da atividade dermonecrótica em venenos homólogos 12 horas após o envenenamento. Esses tratamentos não reduziram edema, eritema, hemorragia e isquemia nas áreas afetadas pelo veneno de L. gaucho. 
Na tentativa de otimizar a utilização de antígenos para imunização de animais e produzir um soro específico, Fernandes Pedrosa et al. (2002) imunizaram coelhos com a proteína recombinante esfingomielinase I (SMase I) e mostraram que o soro obtido era capaz de neutralizar totalmente a reação dermonecrótica induzida pelo veneno de $L$. laeta.

Tambourgi et al. (2004) analisaram a reatividade cruzada dos anticorpos produzidos contra as SMases D recombinantes P1 e P2 de L. intermedia e SMase I de $L$. laeta, contra os venenos de $L$. intermedia, L. laeta e $L$. gaucho. Os resultados obtidos foram indicativos de que é necessária a associação de SMases dessas espécies para obtenção de um soro capaz de neutralizar eficientemente os efeitos tóxicos induzidos pelos venenos.

Seguindo essa proposta, Olvera et al., (2006) clonaram e expressaram SMases $D$ dos venenos de $L$. laeta, $L$. reclusa e $L$. boneti e produziram um soro antiSMases D. Esse soro mostrou capacidade neutralizante para a atividade esfingomielinásica e dermonecrótica induzida por esses venenos. 


\section{OBJETIVO}

O presente estudo tem como objetivo avaliar o potencial neutralizante do soro eqüino hiperimune, produzido contra esfingomileinases $D$ recombinantes de Loxosceles, i.e., SMase I de L. laeta, SMases P1 e P2 de L. intermedia, e comparálo ao do anti-Aracnídico, produzido pelo Instituto Butantan e utilizado na soroterapia humana, sobre a ação tóxica dos venenos de aranhas do mesmo gênero com importância médica no Brasil e América Latina. 


\section{MATERIAL E MÉTODOS}

\subsection{ANIMAIS}

\subsubsection{ARANHAS}

As aranhas Loxosceles gaucho, L. intermedia e L. laeta foram mantidas e criadas no Biotério de Loxosceles do Laboratório de Imunoquímica do Instituto Butantan, a partir de espécimes coletados em São Paulo (SP), Curitiba (PR), Campo Alegre e Lauro Muller (SC).

\subsubsection{COELHOS}

Coelhos machos da raça Nova Zelândia, provenientes do Biotério Central do Instituto Butantan, pesando entre 2,5 e $3 \mathrm{~kg}$, foram utilizados para a realização dos ensaios de dermonecrose e soro neutralização in vivo.

\subsection{VENENOS}

Misturas de venenos de machos e fêmeas das espécies $L$. intermedia, L. laeta e L. gaucho foram obtidas por eletroestimulação, segundo o método de BÜCHERL (1969), com modificações. Este método consiste na aplicação de pulsos de baixa voltagem na região ventral do externo das aranhas, o que faz com que os animais ejetem o veneno pelos ferrões; esse foi aspirado com micropipeta e diluído em solução salina estéril. Para quantificação de proteínas foi utilizado o ensaio de BCA ("Protein Assay Kit", Pierce Biotechnology, Inc, EUA) e a concentração dos venenos 
ajustada para $1 \mu \mathrm{g} / \mu \mathrm{L}$, com solução salina estéril, sendo as amostras aliquotadas e estocadas a $-20^{\circ} \mathrm{C}$.

\subsection{SOROS EQÜINOS HIPERIMUNES}

\subsubsection{SORO ANTI-ARACNÍDICO}

O soro comercial anti-Aracnídico (lote: 0506118) é produzido pela Divisão Bioindustrial do Instituto Butantan pela imunização de cavalos com uma mistura de venenos do escorpião Tityus serrulatus (57\%) e aranhas Phoneutria nigriventer $(21,5 \%)$ e Loxosceles gaucho (21,5\%); a fração IgG do soro é purificada, tratada com pepsina para obtenção da fração $F\left(a b^{\prime}\right)_{2}$, sendo as amostras aliquotadas em frascos.

\subsubsection{SORO ANTI-SMASES D}

O soro anti-SMases $D$ de Loxosceles foi produzido pela Seção de Processamento de Plasmas Hiperimunes da Divisão Bioindustrial, do Instituto Butantan, e corresponde à fração lgG, tratada com pepsina, purificada a partir de uma mistura de soros de cavalos, que foram hiperimunizados com as SMases D recombinantes P1 e P2 de L. intermedia e SMase I de L. laeta. O processo de produção deste soro está protegido por patente, processo oㅜ 0404765-6 de 03.11.2004, depositada no Instituto Nacional da Propriedade Industrial.

\subsubsection{SORO ANTI-BOTRÓPICO}


O soro comercial anti-Botrópico (lote: 0506118) é produzido pela Divisão Bioindustrial do Instituto Butantan pela imunização de cavalos com uma mistura de venenos das serpentes B. jararaca, B. jararacussu, B. moojeni, B. newiedii, B. alternatus, sendo a fração IgG do soro purificada, tratada com pepsina para obtenção da fração $F\left(a b{ }^{\prime}\right)_{2}$, e as amostras aliquotadas em frascos.

\subsection{ANÁLISE DO RECONHECIMENTO DOS VENENOS PELOS SOROS ANTI- ARACNÍDICO E ANTI-SMASES D DE LOXOSCELES}

\subsubsection{DOSAGENS DE ANTICORPOS}

Os títulos de anticorpos dos soros anti-Aracnídico e anti-SMases $D$ frente aos diferentes venenos de Loxosceles foram determinados por ELISA. Neste, microplacas (Costar ${ }^{\circledR}$, Corning Inc., EUA) foram sensibilizadas pela adição de 10 $\mu \mathrm{g} / \mathrm{mL}$ dos venenos de L. intermedia, L. gaucho e L. laeta (100 $\mu \mathrm{L} /$ orifício) em tampão PBS ( $\mathrm{NaCl} 137$ mM, Na $\mathrm{HPO}_{4} 8,1 \mathrm{mM}, \mathrm{KCL}$ 2,7 mM e $\mathrm{KH}_{2} \mathrm{PO}_{4}$ 1,5 mM - pH $7,2)$. Após incubação por $18 \mathrm{~h}$ a $4^{\circ} \mathrm{C}$ em câmara úmida, as placas foram lavadas 3 vezes com PBS e bloqueadas pela incubação com $200 \mu \mathrm{L} /$ orifício de tampão PBS/BSA $5 \%$ por $2 \mathrm{~h}$ a $37^{\circ} \mathrm{C}$. Em seguida, as placas foram lavadas 3 vezes com tampão PBS/Tween-20 0,1\%. Para determinação dos títulos, foram adicionados 100

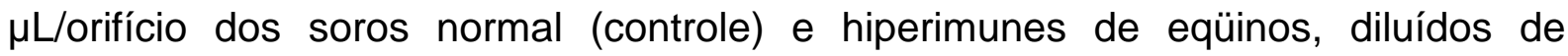
maneira seriada em tampão PBS/BSA 1\%. Após incubação, por $1 \mathrm{~h}$ a temperatura ambiente, as placas foram submetidas a novo ciclo de três lavagens com tampão PBS/Tween-20 0,1\% e adicionados $100 \mu \mathrm{L} /$ orifício de anti-lgG total de cavalo conjugado com peroxidase (Sigma-Aldrich, MO, EUA), diluído 1:3.000 em tampão PBS-BSA $0,1 \%$, seguido da incubação por $1 \mathrm{~h}$ a $37^{\circ} \mathrm{C}$. Após ciclo de três lavagens 
com tampão PBS/Tween-20 $0,1 \%$, as reações foram reveladas pela adição do substrato OPD (ortofenil-diaminobenzidina) e $\mathrm{H}_{2} \mathrm{O}_{2}$ (peróxido de hidrogênio), de acordo com as recomendações do fabricante (Sigma-Aldrich). As placas foram incubadas à temperatura ambiente por 20 min e a reação interrompida pela adição de $50 \mu \mathrm{L}$ /orifício de $\mathrm{H}_{2} \mathrm{SO}_{4} 4 \mathrm{~N}$. A absorbância foi determinada a $\lambda 492 \mathrm{~nm}$ em leitor de placas de ELISA (Multiskan EX, Labsystems, Finlândia).

\subsubsection{DETERMINAÇÃO DAS SUBCLASSES DE IgG PRESENTES NOS SOROS ANTI-ARACNIIDICO E ANTI-SMASES D}

Os títulos das subclasses de $\lg G$ (lgGa, $\lg G b, \lg G c$, $\lg G T$ ) presentes nos soros anti-Aracnídico e anti-SMases $\mathrm{D}$ foram determinados por meio de ELISA de captura. Resumidamente, microplacas (Costar ${ }^{\circledR}$, Corning Inc.) foram sensibilizadas pela adição dos anticorpos monoclonais $(1: 250)$ (Bentil, EUA) específicos para as diferentes subclasses (100 $\mu \mathrm{L} /$ poço) em tampão PBS. Após incubação por uma noite a $4^{\circ} \mathrm{C}$ em câmara úmida, as placas foram lavadas três vezes com PBS e bloqueadas pela incubação com $200 \mu \mathrm{L} /$ orifício de tampão PBS/BSA $5 \%$ por $2 \mathrm{~h}$ a $37^{\circ} \mathrm{C}$. Em seguida, as placas foram lavadas três vezes com tampão PBS e adicionados 100 $\mu \mathrm{L} /$ orifício dos soros normal, anti-Aracnídico e anti-SMases D, diluídos de maneira seriada. A seguir a reação foi desenvolvida com o conjugado específico, como descrito anteriormente.

\subsubsection{ANÁLISES QUALITATIVAS DOS SOROS}

Amostras dos venenos de L. intermedia, L. gaucho ou L. laeta $(10 \mu \mathrm{g})$ foram submetidas à eletroforese vertical em mini-géis de poliacrilamida, em presença de 
dodecil sulfato de sódio (SDS-PAGE), segundo o método descrito por Laemmli (1970). A separação eletroforética foi feita pela aplicação de $100 \mathrm{~V}$ e, após a migração, as bandas foram visualizadas pela impregnação com prata, conforme descrito por MORRISSEY (1980). As massas moleculares relativas das proteínas presentes nas amostras foram determinadas por comparação de migração com uma mistura de proteínas de calibração, com massas conhecidas (BenchMark, "PreStained Protein Ladder", GIBCO, EUA).

As amostras dos venenos separadas em géis de SDS-PAGE foram eletrotransferidas para matrizes de nitrocelulose (Mini-protean TM II, Bio-Rad, Lab., Richmond, CA, EUA), segundo o método descrito por TOWBIN et al. (1979). A transferência foi realizada durante uma noite a $4^{\circ} \mathrm{C}$, sob amperagem constante de 180 mA, em tampão Tris 25 mM, glicina $192 \mathrm{mM}, \mathrm{pH}$ 8,3, metanol 20\%. As membranas de nitrocelulose, contendo os componentes separados dos venenos de L. intermedia, L. gaucho e L. laeta foram bloqueadas com PBS contendo BSA 5\%, por duas horas a $37^{\circ} \mathrm{C}$ e, em seguida, incubadas com os soros anti-Aracnídico ou anti-SMases D (1:2000) diluídos em PBS/BSA 0.1\%, por $1 \mathrm{~h}$ a temperatura ambiente. Decorrido esse período, as membranas foram lavadas três vezes com PBS/Tween-20 $0,1 \%$ por 10 minutos e incubadas com conjugado específico marcado com fosfatase alcalina, diluído 1: 5.000 em PBS/BSA $0.1 \%$, por $1 \mathrm{~h}$ a temperatura ambiente. A seguir, as membranas foram novamente lavadas três vezes com PBS/Tween-20 0,1\% por 10 minutos e a reação foi revelada pela adição do substrato NBT/BCIP (Nitro-Blue tetrazolium chloride / 5-bromo-4-chloro-3'indolyphosphate p-toluidine salt), de acordo com as recomendações do fabricante (Promega, Madison, WI, EUA). 


\subsection{ENSAIOS DE SORONEUTRALIZAÇÃO}

\subsubsection{DETERMINAÇÃO DA ATIVIDADE DERMONECRÓTICA EM COELHOS}

A determinação da atividade dermonecrótica induzida pelos venenos de Loxosceles foi realizada em coelhos. Amostras de $3 \mu \mathrm{g}$ dos venenos de $L$. gaucho, L. intermedia ou L. laeta foram inoculadas, pela via intradérmica, no dorso de coelhos adultos. Amostras de PBS foram inoculadas como controle negativo. Os animais foram examinados ao longo de 72 horas e o tamanho das lesões mensuradas.

\subsubsection{SORONEUTRALIZAÇÃO “IN-VIVO”}

A capacidade neutralizante dos soros anti-Aracnídico e anti-SMases D de Loxosceles foi avaliada segundo a metodologia utilizada pelo Setor de Controle de Qualidade do Instituto Butantan. Para este ensaio, os venenos de L. gaucho, $L$. intermedia ou $L$. laeta foram inoculados no dorso de coelhos pela via intradérmica (dois animais por grupo), concomitantemente à injeção endovenosa de $1 \mathrm{~mL}$ dos antissoros teste, diluídos 1:15. Os animais foram examinados durante os tempos de 24, 48 e 72 horas após o envenenamento, sendo o tamanho das lesões mensuradas. Após 72 horas, os animais foram sacrificados pela injeção de tiopental sódico, $1 \mathrm{~mL} / \mathrm{Kg}$ pela via endovenosa. Os resultados obtidos foram expressos como as médias das porcentagens de soroneutralização obtidas em três ensaios independentes. 


\subsubsection{SORONEUTRALIZAÇÃO “IN VTRO - IN VIVO"}

A capacidade neutralizante dos soros anti-Aracnídico e anti-SMases D de Loxosceles foi também avaliada incubando-se, por $30 \mathrm{~min}$ a $4^{\circ} \mathrm{C}$, amostras contendo $5 \mu \mathrm{g}$ dos venenos de $L$. intermedia, $L$. gaucho ou $L$. laeta com os soros eqüinos diluídos de maneira seriada (diluições de 1:15; 1:30; 1:45; 1:60; 1:90 e 1:120). As misturas foram centrifugadas a $14.000 \mathrm{rpm}$, por $10 \mathrm{~min}$ a $4^{\circ} \mathrm{C}$, os sobrenadantes coletados e injetados no dorso de coelhos (dois animais por grupo), pela via intradérmica. Como controles da reação, amostras dos venenos foram incubadas com soro normal de cavalo ou com salina estéril e processadas como descrito acima. Os animais foram examinados durante os tempos de 24, 48 e 72 horas após o envenenamento, sendo o tamanho das lesões mensuradas. Após 72 horas, os animais foram sacrificados pela injeção de tiopental sódico, $1 \mathrm{~mL} / \mathrm{Kg}$ pela via endovenosa. Os resultados obtidos foram expressos como as médias das porcentagens de soroneutralização obtidas em três ensaios independentes.

\subsubsection{DETERMINAÇÃO DA ATIVIDADE HEMOLÍTICA, DEPENDENTE DE COMPLEMENTO, INDUZIDA PELOS VENENOS DE LOXOSCELES}

\subsubsection{SORO NORMAL HUMANO}

Soro de indivíduos adultos saudáveis foi obtido do sangue com o fenótipo $\mathrm{O}$ $\mathrm{Rh}^{+}$. O sangue foi incubado a $37^{\circ} \mathrm{C}$ e mantido sob refrigeração a $4^{\circ} \mathrm{C}$ para retração do coágulo. Seguiu-se a centrifugação a $1500 \mathrm{rpm}$ por 10 min a $4^{\circ} \mathrm{C}$ e $\mathrm{o}$ soro foi armazenado a $-80^{\circ} \mathrm{C}$. 


\subsubsection{ERITRÓCITOS HUMANOS}

Amostras de sangue $\mathrm{ORh}^{+}$foram coletadas em Alsever $\mathrm{pH}$ 6,1 (114 mM citrato, $27 \mathrm{mM}$ glucose, $72 \mathrm{mM} \mathrm{NaCl}$ ) e os eritrócitos utilizados como alvo nos ensaios para complemento.

\subsubsection{TRATAMENTOS DOS ERITRÓCITOS HUMANOS COM OS VENENOS DE LOXOSCELES}

Um volume de eritrócitos humanos a 1,5\% foi incubado com igual volume de tampão VBS $^{2+}$ contendo concentrações crescentes da mistura de venenos de machos e fêmeas de L. intermedia, L. laeta ou L. gaucho, durante 30 minutos a $37^{\circ} \mathrm{C}$. Eritrócitos incubados com tampão $\mathrm{VBS}^{2+}(2,8 \mathrm{~mm}$ ácido barbitúrico, 145,5 mM $\mathrm{NaCl}, 0,8 \mathrm{mM} \mathrm{MgCl}_{2}, 0,3 \mathrm{mM} \mathrm{CaCl} 2,0,9 \mathrm{mM} \mathrm{Na}$-barbital, $\mathrm{pH}$ 7.2) foram utilizados como controle. As amostras foram lavadas por três vezes e novamente suspensas em $\mathrm{VBS}^{2+}$ para o volume final de $1 \mathrm{~mL}$.

\subsubsection{ENSAIO HEMOLÍTICO}

Amostras de $100 \mu \mathrm{L}$ de eritrócitos humanos tratados ou não com os venenos das três espécies de Loxosceles, em duplicatas, foram adicionados a $50 \mu \mathrm{L}$ de soro humano normal $(\mathrm{SHN})$ e o volume ajustado para $200 \mu \mathrm{L}$ com tampão $\mathrm{VBS}^{2+}$. A lise espontânea ou total dos eritrócitos humanos foi avaliada em amostras de eritrócitos incubadas com $\mathrm{VBS}^{2+}$ ou $\mathrm{H}_{2} \mathrm{O}$, respectivamente. Após a incubação durante $1 \mathrm{~h}$ a $37^{\circ} \mathrm{C}$, as amostras foram centrifugadas a $1.500 \mathrm{rpm}$ durante 3 min e a $4^{\circ} \mathrm{C}$, os 
sobrenadantes coletados e a hemólise mensurada a $\lambda 414 \mathrm{~nm}$ e expressa em porcentagem.

\subsubsection{SORONEUTRALIZAÇÃO DA CAPACIDADE DE INDUÇÃO DA REMOÇÃO DE GLICOFORINA C DAS MEMBRANAS DE ERITRÓCITOS E DA LIGAÇÃO DAS TOXINAS À SUPERFÍCIE DAS CÉLULAS}

Amostras contendo $3 \mu \mathrm{g}$ dos venenos de L. intermedia, L. laeta ou L. gaucho, em $25 \mu \mathrm{L}$ de PBS, foram incubadas por $1 \mathrm{~h}$ a $37^{\circ} \mathrm{C}$ sob agitação com diluições crescentes $(1: 15 ; 1: 150 ; 1: 750 ; 1: 1500)$ dos soros-teste (soros eqüinos: antiBotrópico, anti-Aracnídico ou anti-SMases D) e adicionadas a amostras de $1 \mathrm{~mL}$ de suspensão de hemácias humanas a 1,5\% em $\mathrm{VBS}^{++}$; as misturas foram incubadas em banho-maria a $37^{\circ} \mathrm{C}$ por 30 min sob agitação. Como controles, hemácias foram incubadas, pelo mesmo período, com tampão na ausência de toxinas e/ou soros. As amostras foram lavadas três vezes com VBS ${ }^{++}$, ressuspensas em tampão de FACS (PBS/BSA 0,1\% + azida sódica 0,01\%) e transferidas para microplacas com fundo em $U(25 \mu \mathrm{L} /$ poço). Estas foram incubadas com o anticorpo monoclonal anti-GPC (Bric 4 - BGRL, Reino Unido), na concentração de $1 \mu \mathrm{g} / \mathrm{ml}$ em tampão de FACS. Após incubação por 30 min a $4^{\circ} \mathrm{C}$, as hemácias foram lavadas três vezes, com tampão de FACS, e ressuspensas no mesmo tampão. A seguir, amostras dos anticorpos secundários, anti-cavalo ou anti-camundongo conjugados com FITC (isotiocianato de fluoresceína) (Pierce, IL, EUA, diluídas 1:50, foram adicionadas às células e as placas incubadas por $30 \min$ a $4^{\circ} \mathrm{C}$. As células foram lavadas por três vezes, ressuspensas em $200 \mu \mathrm{L}$ de tampão FACS e a intensidade de fluorescência determinada em citômetro de fluxo (FACScalbur, Becton Dickinson, CA, EUA). 


\subsubsection{DETERMINAÇÃO DA ATIVIDADE ESFINGOMIELINÁSICA DOS VENENOS DE LOXOSCELES}

A determinação da atividade esfingomielinásica dos venenos de Loxosceles foi realizada segundo o método descrito por TOKUMURA et al. (2002); esse método baseia-se na liberação de colina, um dos produtos da hidrólise de esfingomielina (SM) por SMases. O substrato SM (50 $\mu \mathrm{M}$ - Sigma-Aldrich, MO, EUA) foi diluído em tampão HEPES-Salina ( $\mathrm{NaCl} 140 \mathrm{mM}, \mathrm{KCl} 5 \mathrm{mM}, \mathrm{CaCl}_{2} 1 \mathrm{mM}, \mathrm{MgCl}_{2} 1 \mathrm{mM}$, HEPES $10 \mathrm{mM}$ - pH 7,4). Amostras dos venenos, preparados em diluições crescentes, e do substrato foram coincubadas em placas durante 20 min a $37^{\circ} \mathrm{C}$. Posteriormente, 10 $\mu \mathrm{L}$ da mistura composta por colina oxidase ( 1 unidade $/ \mathrm{mL}$ ), peroxidase $(0,06$ unidade/mL) e $50 \mu \mathrm{M}$ de ácido 3-(4-hidroxil-fenil) propiônico em HEPES foram adicionados e a reação prosseguiu por mais $10 \mathrm{~min}$; ao final, a colina liberada é oxidada a betaína e peróxido de hidrogênio. A liberação da colina, com a conseqüente oxidação à betaína, foi acompanhada pela leitura a $\lambda 320 \mathrm{~nm}$ (excitação) e $405 \mathrm{~nm}$ (emissão) em espectrofluorímetro de placa VICTOR.

\subsubsection{DETERMINAÇÃO DA ATIVIDADE ESFINGOMIELINÁSICA RESIDUAL DAS AMOSTRAS DOS VENENOS DE LOXOSCELES}

A atividade esfingomielinásica remanescente nas amostras de venenos, após incubação com os soros eqüinos anti-Botrópico, anti-Aracnídico ou anti-SMases $D$ de Loxosceles, foi determinada pelo do método TOKUMURA et al. (2002), como acima descrito. Resumidamente, amostras de $1 \mu \mathrm{g}$ dos venenos de L. intermedia, L. laeta ou L. gaucho, diluídos em $10 \mu \mathrm{L}$ de tampão HEPES, foram incubadas por 30 min a $37^{\circ} \mathrm{C}$ sob agitação com $20 \mu \mathrm{L}$ dos soros-teste, diluídos de maneira seriada, e 
centrifugadas a $14.000 \mathrm{rpm}$ por $15 \mathrm{~min}$. Os sobrenadantes $(10 \mu \mathrm{L})$, livres de imunocomplexos, foram incubados, por $25 \mathrm{~min}$ a $37^{\circ} \mathrm{C}$, com amostras do substrato SM $(50 \mu \mathrm{M})$. Posteriormente, $10 \mu \mathrm{L}$ da mistura composta por colina oxidase (1 unidade $/ \mathrm{mL})$; peroxidase (0,06 unidade/mL) e $50 \mu \mathrm{M}$ de ácido 3-(4-hidroxil-fenil) propiônico em HEPES foram adicionados e a reação prosseguiu por mais 10 min. Após esse período foi realizada a leitura da placa, a $\lambda 320 \mathrm{~nm}$ (excitação) e \405nm (emissão), em espectrofluorímetro de placa VICTOR e a porcentagem de soroneutralização calculada.

\subsection{ANÁLISE ESTATÍSTICA}

Os resultados obtidos foram analisados estatisticamente pelo teste t'Students, sendo consideradas significativas as diferenças com $p<0.05^{*}$.

\section{RESULTADOS}

\subsection{ANÁLISE DO RECONHECIMENTO DOS VENENOS PELOS SOROS ANTI- ARACNÍDICO E ANTI-SMASES D DE LOXOSCELES}

\subsection{1 por Western Blot}

A análise eletroforética dos venenos de L. intermedia, L. laeta e L. gaucho revelou a presença de um grande número de bandas com massa molecular entre 18 e 120,0 kDa. A avaliação comparativa dos perfis eletroforéticos dos venenos mostrou diferenças não só no número como também na intensidade das bandas, embora, todos apresentem componentes na região de $30-35 \mathrm{kDa}$, massas correspondentes às das SMases D (Figura 3 A). 
A análise do reconhecimento das proteínas dos venenos de Loxosceles pelos soros eqüinos anti-Aracnídico e anti-SMases $\mathrm{D}$ foi realizada pela técnica de Western blot. Os resultados obtidos mostraram que o soro anti-Aracnídico foi capaz de reconhecer, embora com intensidades distintas, a maioria dos componentes presentes nos venenos de L. intermedia, L. laeta e L. gaucho. O soro anti-SMases D, como esperado, reconheceu bandas na região de 30-35 kDa, correspondentes as SMases $D$ presentes nestes venenos. $O$ soro anti-SMases $D$ teve ainda a capacidade de reconhecer componentes dos venenos de $L$. laeta e $L$. intermedia na faixa de $65 \mathrm{kDa}$ (Figura $3 \mathrm{~B}$ ). 

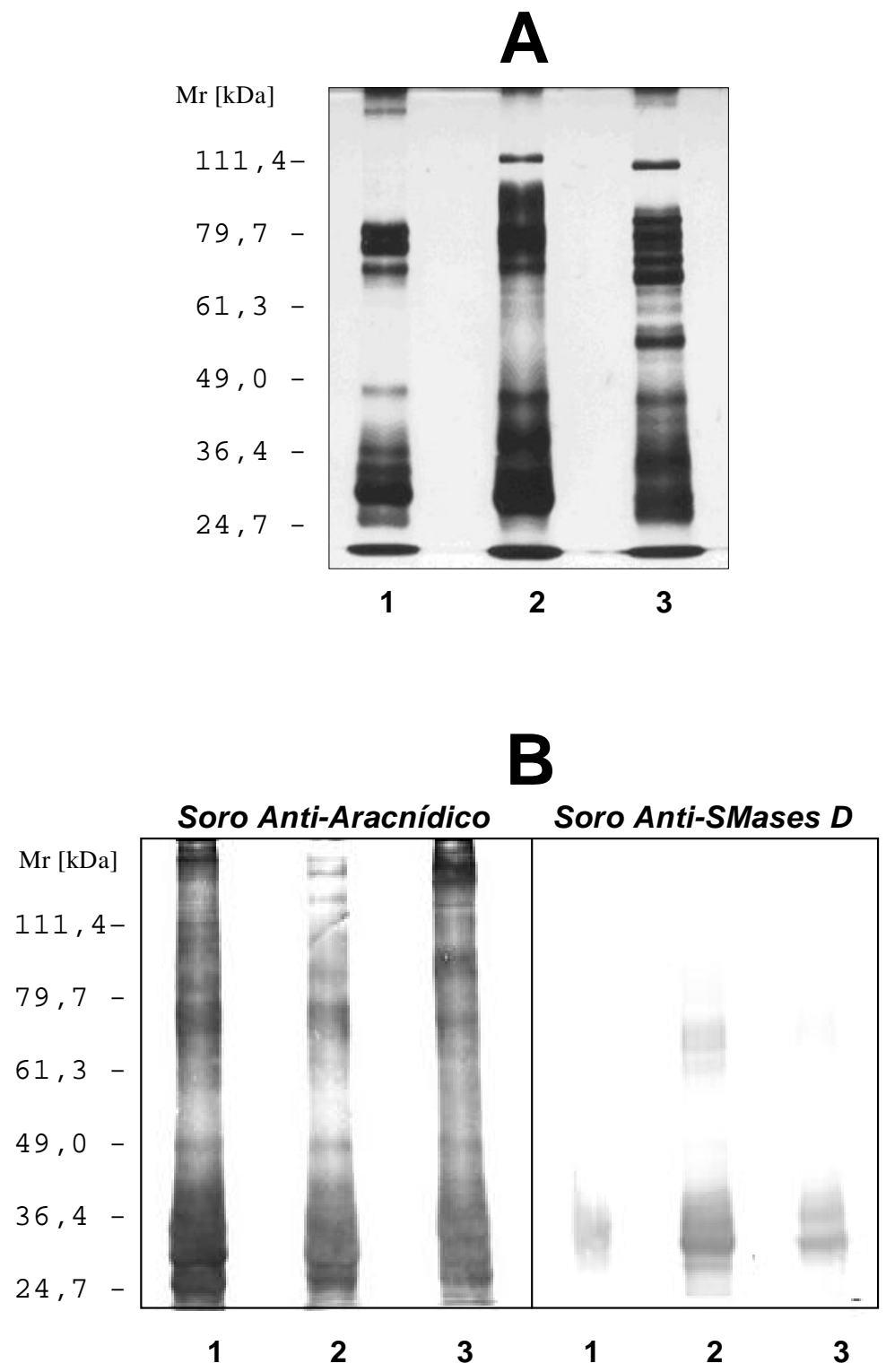

FIGURA 3: RECONHECIMENTO DOS VENENOS DE Loxosceles PELOS SOROS ANTIARACNÍDICO E ANTI-SMASES D. [A] Amostras contendo $10 \mu \mathrm{g}$ dos venenos de $L$. gaucho (1), L. intermedia (2) e L. laeta (3) foram submetidas a eletroforese em SDS-PAGE a $12 \%$ em condições não redutoras. As bandas foram reveladas por impregnação pela prata. [B] As amostras submetidas à eletroforese foram, subseqüentemente, eletrotransferidas para membranas de nitrocelulose, as quais foram incubadas com os soros anti-Aracnídico ou antiSMases $D$. As reações foram reveladas pela adição do conjugado específico marcado com fosfatase alcalina e reveladas com o substrato NBT/BCIP. 


\subsection{2 por ELISA - TÍTULOS DE ANTICORPOS}

Os títulos dos soros anti-Aracnídico e anti-SMases $\mathrm{D}$ foram determinados frente aos venenos das três espécies de Loxosceles e às SMases D por ELISA. Como controle das reações, soro normal de cavalo foi testado frente aos mesmos antígenos.

As Tabelas 1 e 2 mostram que ambos os soros apresentaram títulos significativos de anticorpos contra todos os antígenos testados. Entretanto, quando comparados, o soro anti-Aracnidico apresentou títulos superiores, para o veneno de L. gauch, do que o soro anti-SMases D. Já o soro anti-SMases $D$ apresentou títulos mais altos para o veneno de $L$. intermedia e toxinas recombinantes P1 e P2 de L. intermedia e SMase I de L. laeta. Os dois soros apresentaram títulos similares frente ao veneno de $L$. laeta. 
TABELAS 1 e 2 : Títulos de Anticorpos dos Soros anti-Aracnídico e anti-SMases D. Placas de ELISA foram sensibilizadas com $100 \mu \mathrm{l}(10 \mu \mathrm{g} / \mathrm{ml})$ das amostras de venenos de $L$. gaucho, $L$. intermedia e $L$. laeta [TABELA 1] ou toxinas recombinantes [TABELA 2] e, posteriormente, incubadas com diluições crescentes dos soros anti-Aracnídico, anti-SMases D ou normal de cavalo. As reações foram reveladas pela adição do conjugado anti-lgG de cavalo marcado com peroxidase e, a seguir, do substrato específico. Os títulos foram determinados como a maior diluição dos soros experimentais, cujas D.O.s, medidas a $492 \mathrm{~nm}$, eram três vezes superiores às obtidas para o soro normal na mesma diluição. Os dados apresentados são representativos de três experimentos.

TABELA 1 - Títulos dos soros frente os venenos de Loxosceles

\begin{tabular}{ccc}
\hline Venenos & Soro anti-Aracnídico & Soro anti-SMases D \\
\hline Loxosceles gaucho & $1: 512.000$ & $1: 128.000$ \\
\hline Loxosceles intermedia & $1: 128.000$ & $1: 256.000$ \\
\hline Loxosceles laeta & $1: 128.000$ & $1: 128.000$ \\
\hline
\end{tabular}

TABELA 2 - Títulos dos soros frente às toxinas recombinantes

SMases D

Soro anti-Aracnídico

Soro anti-SMases D

P1

$1: 256.000$

$1: 512.000$

P2

$1: 256.000$

$1: 512.000$

SMase I

$1: 512.000$

$1: 1.024 .000$ 


\subsection{DETERMINAÇÃO DOS TíTULOS DAS SUBCLASSES DE IgG DOS SOROS}

Os títulos das subclasses de $\lg G$ (IgGT, IgGa, IgGb e $\lg G c$ ) nos soros antiAracnídico e anti-SMases D foram determinados por ELISA de captura. Como controle das reações, soro normal de cavalo foi também testado para as subclasses de IgG de eqüinos. Os títulos foram determinados com a maior diluição dos soros experimentais, cujas D.Os fossem uma vez superior àquelas obtidas para o soro normal.

A Tabela 3 mostra que o soro anti-SMases D apresentou títulos significativamente maiores de todas as subclasses de lgG do que o anti-Aracnídico.

TABELA 3: Placas de ELISA foram sensibilizadas com $100 \mu \mathrm{l}$ das amostras dos soros antiisotipos de $\lg$ de cavalo (IgGT, IgGa, IgGb e $\lg G$ c) diluídos 1:250 e, posteriormente, incubadas com diluições crescentes dos soros anti-Aracnídico, anti-SMases $D$ ou normal de cavalo. As reações foram reveladas pela adição do conjugado anti-IgG de cavalo marcado com peroxidase e, a seguir, do substrato específico. Os títulos foram determinados como a maior diluição dos soros experimentais, cujas DOs, medidas a $492 \mathrm{~nm}$, fossem uma vez superior às obtidas para o soro normal na mesma diluição. Os dados apresentados são representativos de três experimentos.

Tabela 3 - Títulos das subclasses de IgG dos soros

$$
\text { Isotipos Anti-Aracnídico Anti-SMases D }
$$

\begin{tabular}{lcc}
\hline IgGT & $1: 5.000$ & $1: 80.000$ \\
IgGa & $<1: 5.000$ & $1: 160.000$ \\
IgGb & $1: 10.000$ & $>1: 640.000$ \\
IgGc & $<1: 5.000$ & $1: 40.000$ \\
\hline
\end{tabular}




\subsection{ENSAIOS DE SORONEUTRALIZAÇÃO}

\subsubsection{DA ATIVIDADE DERMONECRÓTICA}

A capacidade de induzir dermonecrose foi avaliada pela inoculação intradérmica de $3 \mu \mathrm{g}$ dos venenos de L. gaucho, L. intermedia ou L. laeta em coelhos, sendo as áreas das lesões mensuradas ao longo de 72 horas. Os animais receberam PBS como controle negativo da reação. A Figura 4 mostra que o veneno de L. intermedia induziu uma menor lesão dermonecrótica, durante as 72 horas, do que as peçonhas de L. gaucho e L.laeta.

O potencial neutralizante dos soros anti-Aracnídico e anti-SMases D foi avaliado pela metodologia utilizada no Setor de Controle de Qualidade do Instituto Butantan, SP. Para este ensaio, $3 \mu \mathrm{g}$ dos venenos de L. intermedia, L. gaucho ou L. laeta foram inoculados no dorso de coelhos pela via intradérmica, concomitantemente, a injeção endovenosa de $1 \mathrm{~mL}$ dos soros teste na diluição de 1:15. A eficiência neutralizante dos soros foi determinada pela inibição do desenvolvimento da lesão dermonecrótica durante as 72 horas.

A Figura 5 A mostra que os soros Anti-Aracnídico e Anti-SMases $D$ foram igualmente eficientes em neutralizar a atividade dermonecrótica do veneno de L. gaucho ao longo das 72 horas. No entanto, para os venenos de L. intermedia e L. laeta, o soro anti-SMases D se mostrou mais eficiente na neutralização (Figuras 5 B e C, respectivamente).

A atividade neutralizante dos soros sobre a atividade dermonecrótica foi também testada em ensaios in vitro - in vivo, nos quais a atividade remanescente das amostras de venenos pré-incubadas com os soros normal (diluição 1:15), anti- 
Aracnídico ou anti-SMases $D$, nas diluições de 1:15, 1:30, 1:45, 1:60, 1:75, $1: 90$ e 1:120 foi determinada em coelhos, após 72 horas da inoculação intradérmica das misturas.

Os resultados obtidos mostram que o soro anti-SMases D apresentou potencial neutralizante significantemente maior que o anti-Aracnídico para o veneno de L. laeta e similar para os venenos de L. gaucho e L. intermedia (Figuras 5 D, E, $\mathbf{F}$, respectivamente).

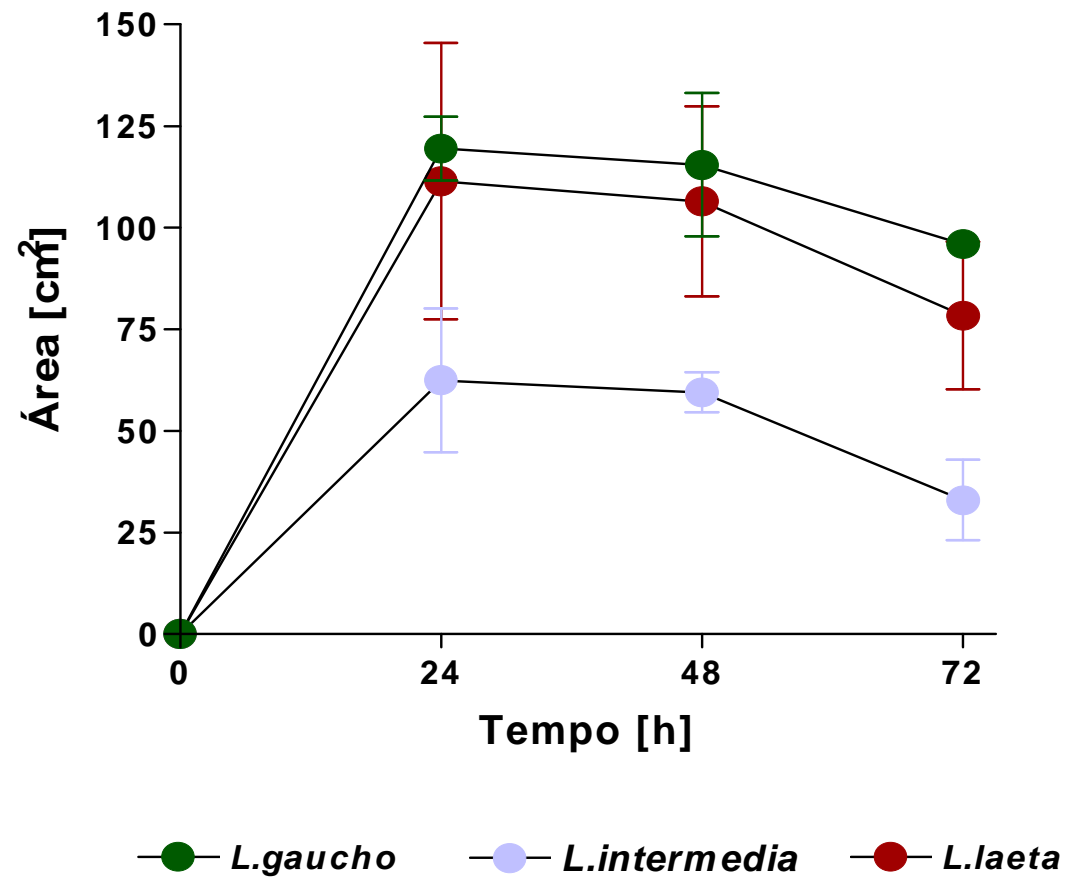

FIGURA 4: ATIVIDADE DERMONECRÓTICA INDUZIDA PELOS VENENOS DE LOXOSCELES. Coelhos foram inoculados, pela via intradérmica, com $3 \mu \mathrm{g}$ dos venenos de Loxosceles. As áreas das lesões foram determinadas durante o período de 72 horas após inoculação. Os resultados foram expressos com as médias das áreas das lesões, determinadas em três ensaios independentes. 

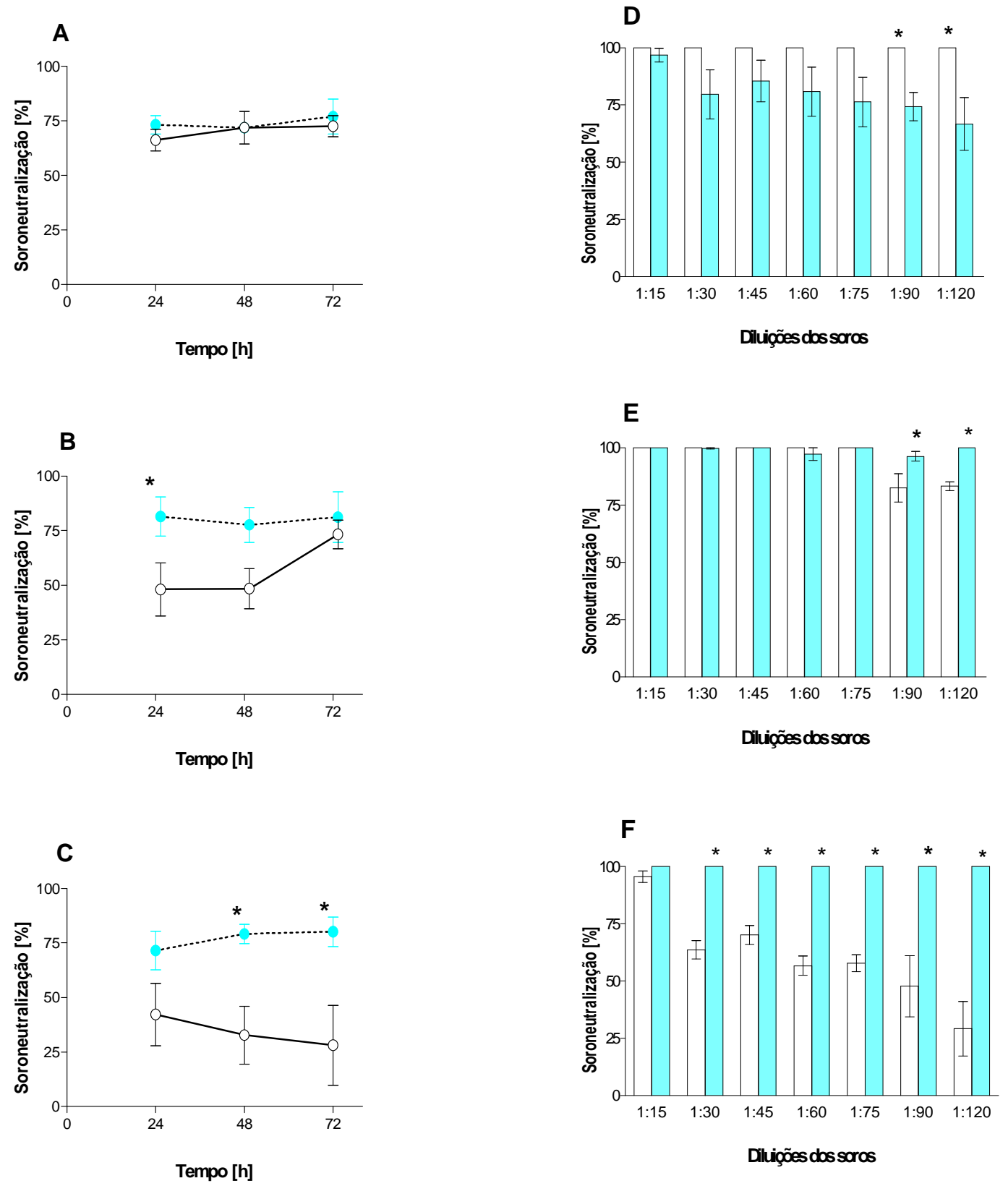

FIGURA 5: SORONEUTRALIZAÇÃO DA ATIVIDADE DERMONECRÓTICA INDUZIDA PELOS VENENOS DE Loxosceles. Ensaio "in vivo": Grupos de coelhos foram inoculados com $3 \mu \mathrm{g}$ dos venenos de L. gaucho [A], L. intermedia [B], L. laeta [C] e, concomitantemente, injetados com $1 \mathrm{~mL}$ dos soros anti-Aracnídico $(\mathrm{O})$ ou anti-SMases D (•), diluídos 1:15 pela via endovenosa diluídos. As áreas das lesões foram determinadas durante o período de 72 horas após inoculação. Ensaio "in vitro in vivo": Amostras contendo $5 \mu \mathrm{g}$ dos venenos de [D] L. gaucho, [E] L. intermedia e [F) L. laeta incubadas por $1 \mathrm{~h}$ a $37^{\circ} \mathrm{C}$ com diluições crescentes dos soros anti-Aracnídico ( $\square$ ) e antiSMases $D(\square)$ e, a seguir, centrifugadas a $14.000 \mathrm{rpm}$, por $15 \mathrm{~min}$. Os sobrenadantes foram inoculados, pela via intradérmica no dorso dos coelhos. As áreas das lesões dermonecróticas foram mensuradas, às 72 horas após a inoculação. Os resultados foram expressos com as médias das áreas das lesões e as porcentagens de soroneutralização, determinadas em três ensaios independentes $\left({ }^{*} p<0,05\right)$. 


\subsubsection{DA ATIVIDADE HEMOLÍTICA}

Amostras de eritrócitos humanos foram incubadas com concentrações crescentes dos venenos de L. intermedia, L. laeta e L. gaucho por 30 minutos a $37^{\circ} \mathrm{C}$. Após várias lavagens das células, foram adicionados tampão ou soro humano normal, como fonte de complemento, e as placas incubadas por 60 minutos a $37^{\circ} \mathrm{C}$. A extensão da lise celular foi determinada e a porcentagem de hemólise calculada. A Figura 6 mostra que os venenos das três espécies de Loxosceles foram capazes de tornar os eritrócitos humanos susceptíveis à lise mediada por complemento autólogo, de forma dose dependente. Na concentração de $3 \mu \mathrm{g} / \mathrm{mL}$, todos os venenos induziram hemólises com valores entre 70 e 100\% e, com base nesses dados, esta concentração foi selecionada para ser utilizada nos ensaios de soroneutralização da atividade hemolítica.

A clivagem de glicoforina $C$ é um evento fundamental para a ocorrência da hemólise dependente de complemento, induzida por ação indireta das SMases D do veneno de Loxosceles sobre as superfícies dos eritrócitos (TAMBOURGl et al., 2000). Tal evento foi utilizado para se avaliar o potencial neutralizante dos soros com relação ao fenômeno de hemólise dependente de complemento. Para tanto, 3 $\mu \mathrm{g}$ dos venenos de Loxosceles e diluições (1:15; 1:150; 1:750 e 1:1500) dos sorosteste (anti-Aracnídico, anti-SMases D ou anti-Botrópico) foram incubados com os eritrócitos humanos a $37^{\circ} \mathrm{C}$ por 1 hora. Como controle positivo e negativo das reações, amostras de eritrócitos foram incubadas somente com veneno ou tampão, respectivamente. Após esse período, as células foram lavadas e incubadas com anticorpo monoclonal anti-GPC e, subseqüentemente, com conjugado marcado com fluoresceína. 
A Figura 7 A mostra que o soro anti-Aracnídico somente foi mais eficaz, do que o anti-SMases $D$, em inibir a indução da remoção de GPC dos eritrócitos tratados com o veneno de L. gaucho; para as peçonhas de $L$. intermedia e L. laeta, o soro anti-SMases $D$ apresentou maior potencial neutralizante desta atividade. Nas mesmas condições experimentais o soro anti-botrópico não foi capaz de neutralizar tal ação (dados não mostrados).

O potencial neutralizante dos soros frente à capacidade de ligação das SMases $D$ dos venenos de Loxosceles às membranas dos eritrócitos humanos, foi avaliado através de ensaios de citometria de fluxo. Assim, amostras contendo os venenos de L. intermedia, L. laeta ou L. gaucho, e as diluições de 1:15; 1:150; 1:750; 1:1500 dos soros-teste (anti-Botrópico, anti-Aracnídico ou anti-SMases D) foram adicionadas a amostras da suspensão de hemácias humanas. Posteriormente, essas misturas foram incubadas a $37^{\circ} \mathrm{C}$ por 30 minutos sob agitação. Como controles, hemácias foram incubadas, pelo mesmo período, com tampão ou venenos, na ausência de anticorpos. Após várias lavagens, as células foram incubadas com anticorpos anti-SMases $D$ e a seguir com antissoro conjugado marcado com fluoresceína.

Os resultados mostram que o soro anti-SMases $D$ foi mais eficiente em inibir a ligação das toxinas dos três venenos de Loxosceles à membrana dos eritrócitos humanos, em todas as diluições testadas, quando comparado ao soro antiAracnídico $\left({ }^{*} p<0.05\right)$ (Figura 7 B). Nas mesmas condições experimentais o soro anti-botrópico não foi capaz de neutralizar tal atividade (dados não mostrados). 


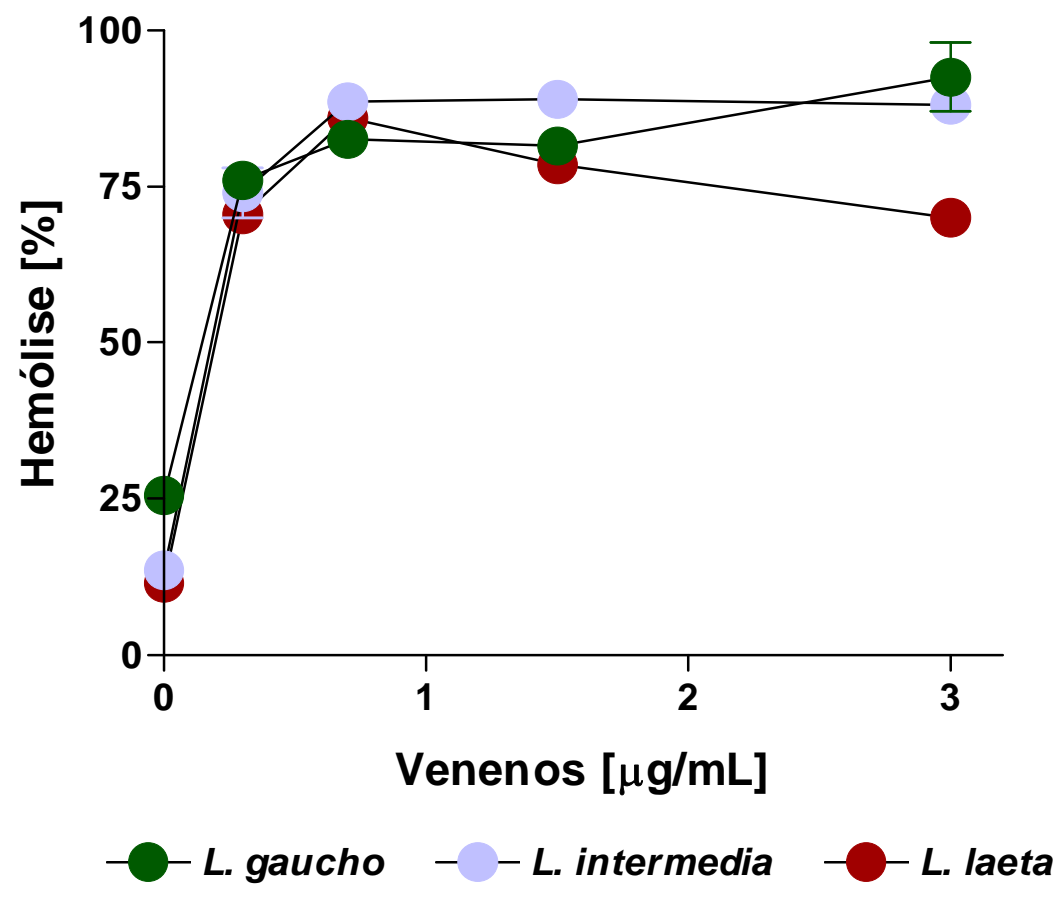

FIGURA 6: HEMÓLISE DEPENDENTE DE COMPLEMENTO INDUZIDA PELOS VENENOS DE Loxosceles. Amostras de eritrócitos humanos pré-tratadas com concentrações crescentes dos venenos de $L$. gaucho, $L$. intermedia e $L$. laeta foram incubadas com soro humano normal e a hemólise determinada. Resultados representativos de dois ensaios independentes. 
A

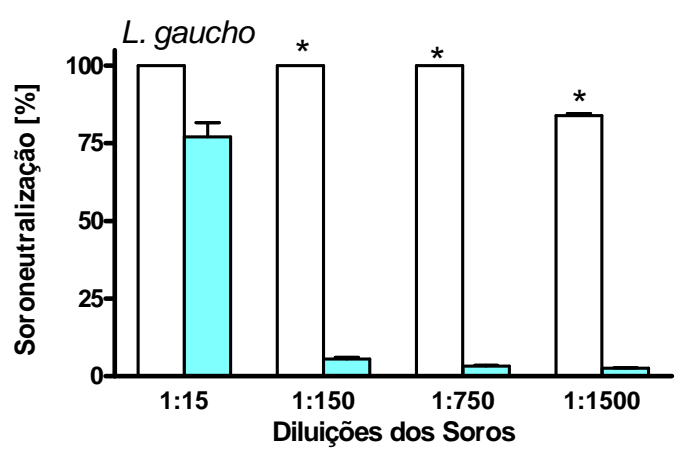

L. intermedia

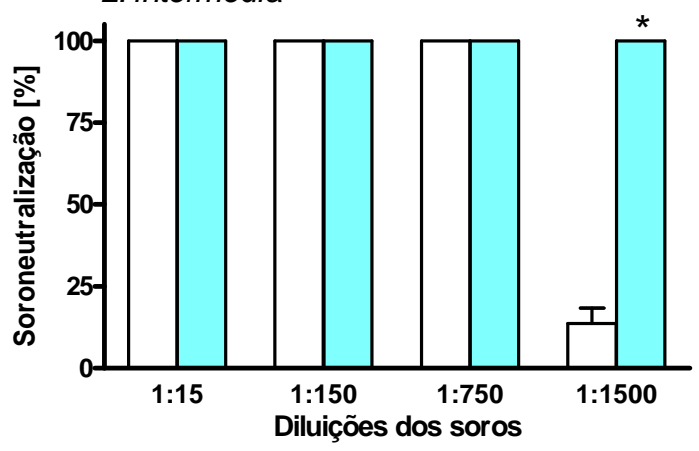

L. laeta

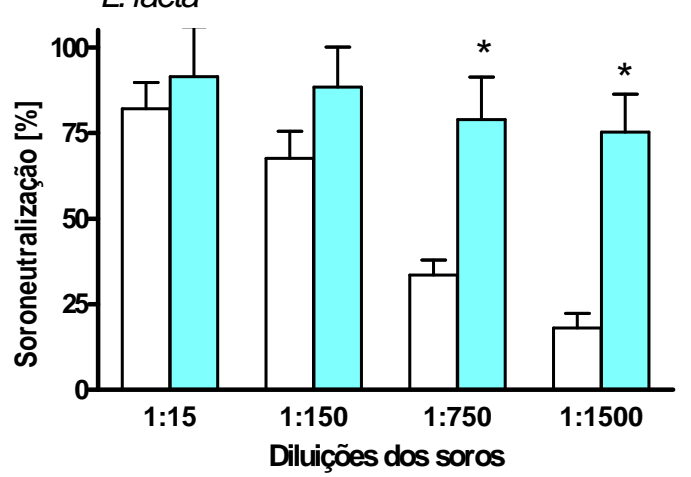

B

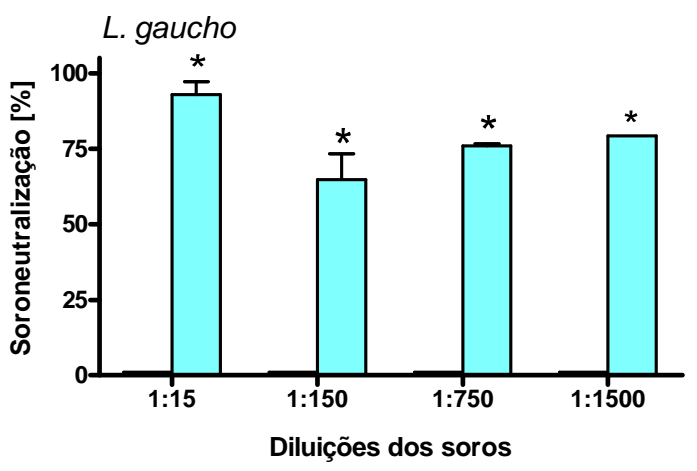

L. intermedia
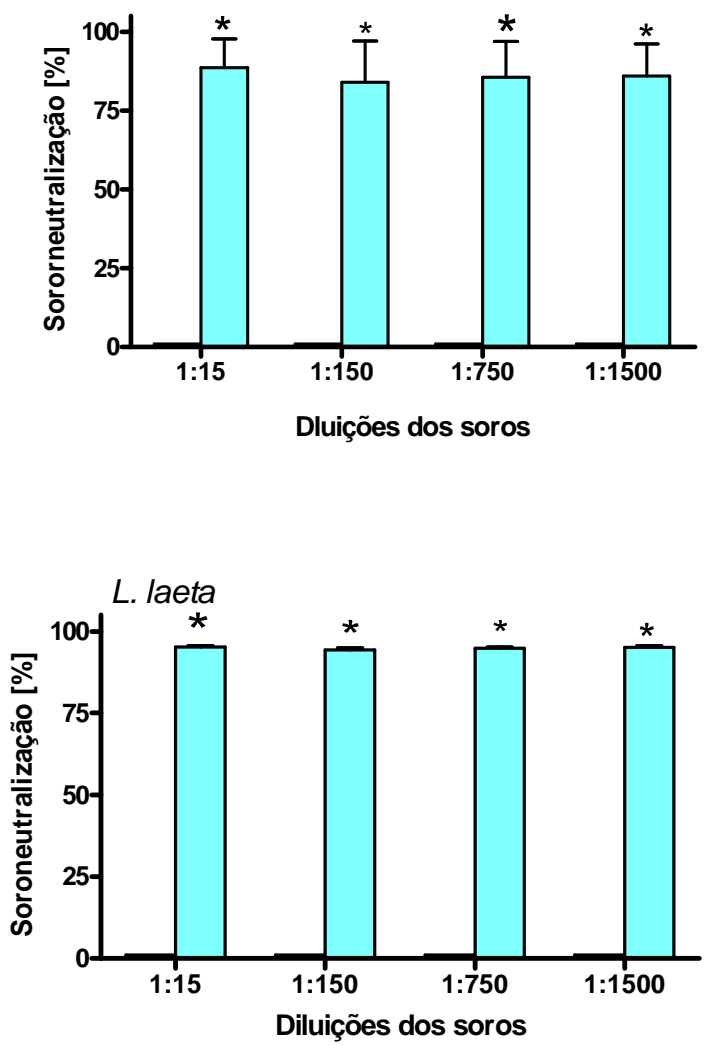

FIGURA 7: SORONEUTRALIZAÇÃO DA ATIVIDADE HEMOLÍTICA INDUZIDA PELOS VENENOS DE Loxosceles. [A] Inibição da remoção de GPC dos eritrócitos, induzidas pelos venenos de $L$. gaucho, $L$. intermedia e $L$. laeta pelos soros antiAracnídico ( $\square$ ) ou anti-SMases D ( $\square$ ); [B] Inibição da ligação das SMases D dos venenos de $L$. gaucho, $L$. intermedia e $L$. laeta, às membranas de eritrócitos humanos pelos soros anti-Aracnídico ( $\square$ ) e anti-SMases D ( $\square$ ). Resultados representativos de dois ensaios independentes. ${ }^{*} p<0,05$ 


\subsubsection{DA ATIVIDADE ESFINGOMIELINÁSICA D}

A determinação da atividade esfingomielinásica dos venenos de Loxosceles foi realizada pelo método descrito por TOKUMURA et al. (2002). A Figura 8 revela que os venenos das três espécies foram capazes de hidrolisar esfingomielina de forma dose-dependente. No entanto, tal atividade parece ser maior em L. gaucho, uma vez que concentrações inferiores a $250 \mathrm{ng}$ deste veneno foram capazes de hidrolisar o substrato, com uma intensidade duas vezes maior do que a dos venenos de L. intermedia e L. laeta. Para os ensaios de soroneutralização da atividade esfingomielinásica foi utilizada a dose de $1 \mu \mathrm{g}$, uma vez que com essa foram obtidos valores semelhantes de hidrólise do substrato para os três venenos de Loxosceles.

A neutralização da atividade esfingomielinásica dos venenos de Loxosceles pelos soros-teste, anti-Aracnídico e anti-SMases D e pelo controle negativo, o soro anti-Botrópico, foi realizada incubando-se amostras de $1 \mu \mathrm{g}$ dos venenos de L. laeta, L. intermedia ou L. gaucho com os soros puros ou diluídos. Após o período de incubação, as amostras foram centrifugadas e os sobrenadantes incubados com esfingomielina e a hidrólise determinada.

A Figura 9 mostra que 0 soro anti-SMases $D$ tem maior potencial neutralizante para a atividade esfingomielinásica presente no veneno de L. laeta, do que o anti-Aracnídico, e uma melhor ação inibitória para o de L. intermedia nas maiores diluições. Para o veneno de $L$. gaucho, o soro anti-Aracnídico foi mais eficaz na neutralização dessa ação do que o soro anti-SMases D. Nas mesmas condições experimentais o soro anti-botrópico não foi capaz de neutralizar significativamente tal atividade (0-10\% de neutralização - dados não mostrados). 


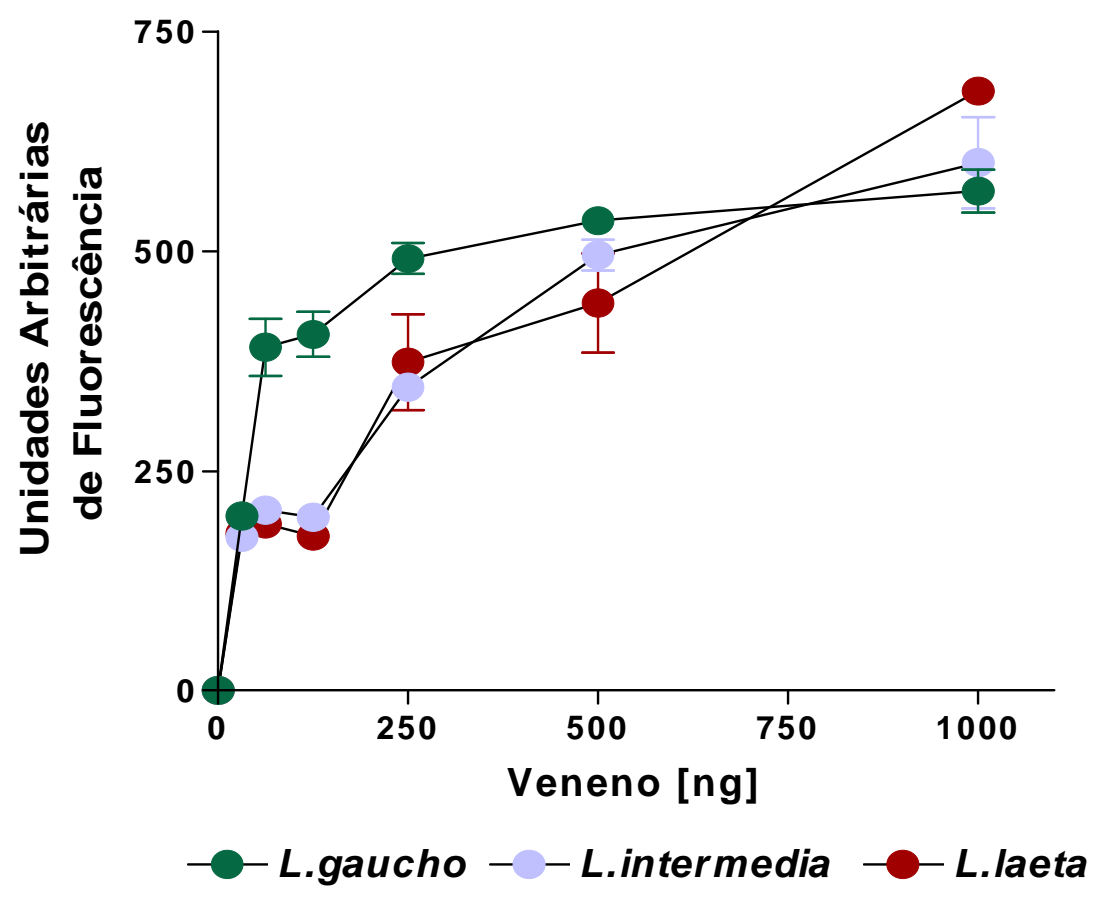

FIGURA 8: ATIVIDADE ESFINGOMIELINÁSICA DOS VENENOS DE LOXOSCELES. Amostras contendo concentrações crescentes dos venenos de Loxosceles foram incubadas com esfingomielina. Após 30 minutos a $37^{\circ} \mathrm{C}$, foi adicionada a solução contendo colina-oxidase e as reações de hidrólise foram quantificadas em fluorímetro de placa. Resultados representativos de dois ensaios independentes. 

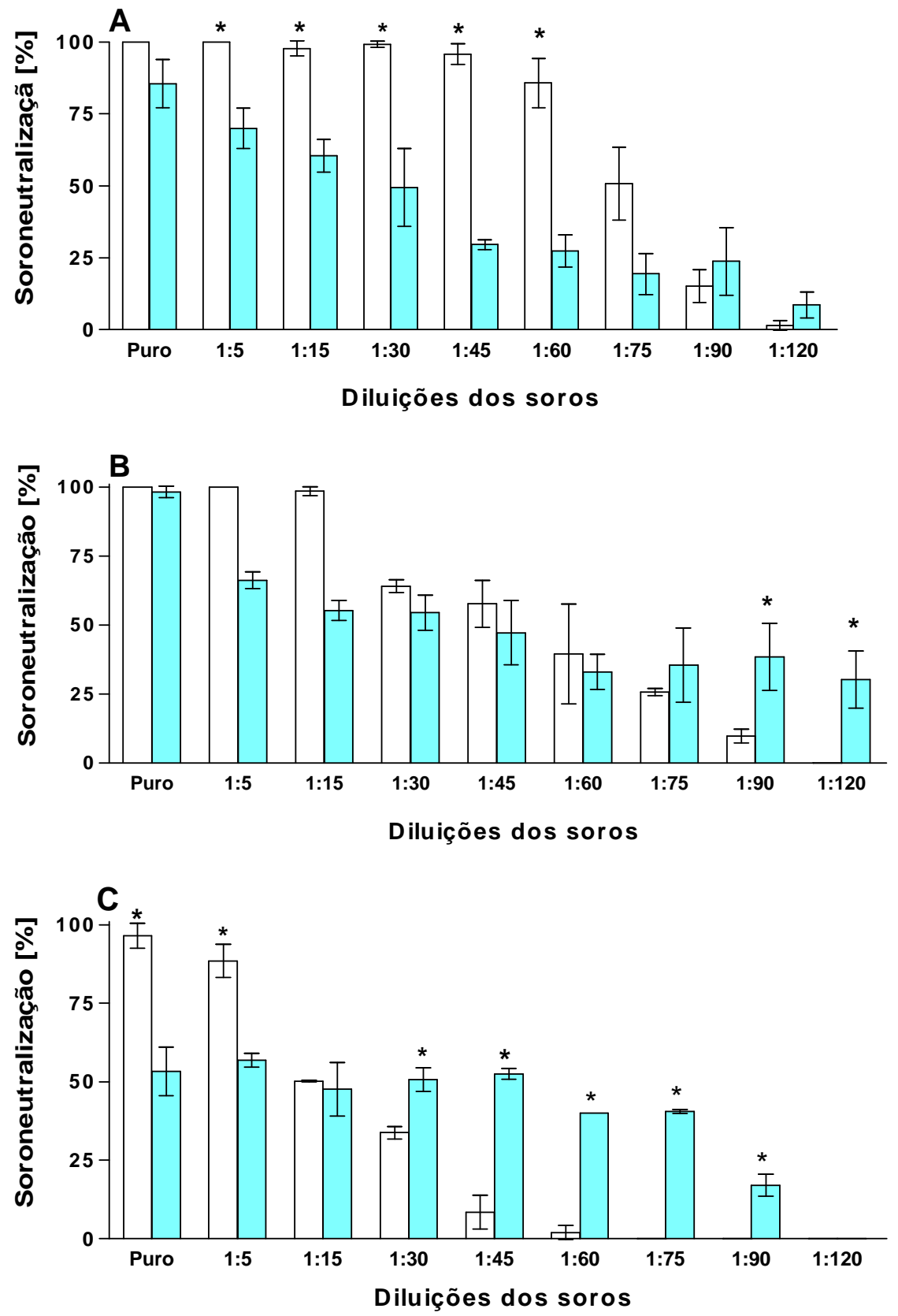

FIGURA 9: DETERMINAÇÃO DA ATIVIDADE ESFINGOMIELINÁSICA RESIDUAL DAS AMOSTRAS DOS VENENOS DE Loxosceles. Amostras dos venenos $L$. gaucho [A], L. intermedia [B] e L. laeta [C] foram incubados por 1 hora com os soros anti-Aracnídico ( $\square$ ) e anti-SMases D ( $\square$ ) e centrifugadas a $14.000 \mathrm{rpm}$ por 15 minutos. Posteriormente, os sobrenadantes foram incubados com 0 substrato, as reações de hidrólise mensuradas e a porcentagem de neutralização calculada. Resultados representativos de dois ensaios independentes. ${ }^{*} p<0,05$ 


\section{DISCUSSÃO}

O envenenamento por aranhas do gênero Loxosceles é a forma mais grave de araneísmo no Brasil, principalmente nas regiões Sudeste e Sul do país (FUNDAÇÃO NACIONAL DE SAÚDE, 1998). O veneno destas aranhas causa lesão dermonecrótica e/ou desencadeia reação sistêmica, cujas características mais graves são a hemólise, coagulação intravascular além da possível evolução para insuficiência renal aguda. Entre as espécies de Loxosceles existentes no Brasil, três são consideradas de importância médica devido à alta incidência de acidentes a elas atribuída: L. gaucho, a principal responsável por acidentes no estado de São Paulo, L. intermedia e L. laeta espécies que estão presentes nos estados do Paraná e Santa Catarina, respectivamente (CARDOSO et al., 1998; CADERNO DE SAÚDE DE CURITIBA, 1993).

Os venenos das aranhas Loxosceles são uma mistura de vários componentes protéicos. Esses venenos possuem uma composição complexa, contendo diferentes toxinas. Nas diferentes espécies de Loxosceles a presença da esfingomielinase D (32-35 KDa) foi associada aos principais efeitos cutâneos e sistêmicos do envenenamento, como dermonecrose e hemólise intravascular. TAMBOURGI et al., (2002 e 2004) clonaram e expressaram as SMases D dos venenos L. intermedia (P1 e P2) e de L. laeta (SMase I) e verificaram que o soro experimental produzido frente essas toxinas tinha a capacidade de reconhecer os venenos brutos das três espécies de Loxosceles de importância médica no Brasil. OLVERA, et al., 2007 utilizando esfingomielinases $D$ recombinantes de importância médica nas Américas (L. laeta, L. boneti e L. reclusa), produziu um soro equino e observou o potencial e a reatividade cruzada e potencial neutralizante da atividade enzimática para os 
venenos dessas três espécies, ressaltando a proposta do soro específico antiSMases D recombinantes.

Baseado nesses dados e com o propósito de tentar melhorar a qualidade do soro produzido para a terapia humana nos casos de loxoscelismo, o Laboratório de Imunoquímica em conjunto com a Divisão Bioindustrial do Instituto Butantan utilizou as SMases D recombinantes de Loxosceles intermedia e Loxosceles laeta na imunização de cavalos para a produção de um novo soro, denominado de antiEsfingomielinases D. De forma geral, este soro foi produzido baseado em métodos estabelecidos pelo setor de Divisão Bioindustrial do Instituto Butantan. Resumidamente, para tanto, para cada toxina foram imunizados dois cavalos, que ao longo de sete imunizações tiveram os títulos de anticorpos determinados. Após o sétimo ciclo de imunização, foram selecionados para a composição do soro antiSMases $D$ os soros dos cavalos com os melhores títulos frente às toxinas recombinantes. Os soros escolhidos foram tratados com ácido caprílico para isolamento da fração lgG e a seguir com pepsina para remoção da fração Fc das imunoglobulinas. O produto final preparado pela Divisão Bioindustrial do Instituto Butantan, correspondente à mistura dos soros individuais purificados, foi esterilizado por filtração e aliquotado em frascos de $2 \mathrm{~mL}$. Como já mencionado em Material e Métodos o processo de produção do soro anti-SMases D está protegido por patente.

A partir da produção deste antissoro foi definido o objetivo do presente estudo que consistiu na avaliação do potencial neutralizante do soro eqüino anti-SMases D sobre as ações tóxicas dos venenos das aranhas Loxosceles, comparando-o ao do anti-Aracnídico, utilizado na terapia para loxoscelismo no Brasil.

Como avaliado por ELISA, os soros foram capazes, embora com títulos variáveis, de reconhecer as peçonhas de L. gaucho, L. laeta e L. intermedia. Essa observação está de acordo com os dados obtidos por BÁRBARO et al. (1994) que 
mostraram que o soro anti-Aracnídico e um outro soro experimental anti-Loxosceles (produzido frente os venenos das três espécies acima mencionadas) eram capazes de reagir com os três venenos.

Analisando individualmente os títulos de anticorpos presentes nos soros para os venenos de Loxosceles, os dados mostram que o soro anti-SMases D apresentou títulos mais altos para o veneno de L. intermedia, menor para o veneno de L. gaucho e igual título para o veneno de L. laeta, quando comparado ao anti-Aracnídico. Para as toxinas recombinantes o soro anti-SMases $D$ apresentou títulos significativamente superiores frente às toxinas P2 de L. intermedia e SMase I de L. laeta. O fato dos dados mostrarem títulos elevados para as toxinas, quando comparado aos venenos, já era esperado (TAMBOURGI et al., 2004), visto que os animais são imunizados com essas toxinas. Entretanto é importante ressaltar que o soro anti-SMases D, apesar de ser produzido frente a toxinas purificadas, apresentou títulos similares ou iguais quando comparado ao anti-Aracnídico produzido contra o veneno total, ressaltando a importância do reconhecimento desse componente tóxico nos venenos de Loxosceles.

A análise eletroforética dos venenos mostrou que eles possuem perfis distintos de proteínas em sua composição. Entretanto, as proteínas na faixa de massa molecular em torno de $32-35 \mathrm{kDa}$, correspondente as SMases $\mathrm{D}$, estão presentes nos três venenos. Variações inter e intra-espécies foram também descritas por DE OLIVEIRA et al. $(1999,2005)$ composição das peçonhas de machos e fêmeas de L. intermedia e L. laeta e por PRETEL et al. (2005) de L. gaucho e L. adelaida.

A análise do perfil de reconhecimento dos venenos pelos soros testes foi realizada por Western blot. Como resultado, foi observado que o soro antiAracnídico teve maior capacidade de reconhecer os componentes dos venenos de 
Loxosceles. O soro anti-SMases D, por outro lado, reagiu com componentes na faixa de massa molecular entre 30-35 kDa. Essas observações já eram esperadas, uma vez que o soro anti-Aracnídico foi produzido frente ao veneno total de L. gaucho e o anti-SMases D contra as isoformas recombinantes de L. intermedia e L. laeta. Ainda, para o veneno de $L$. laeta, o soro anti-SMases $D$ teve a capacidade de reconhecer componentes na faixa $65 \mathrm{kDa}$, que podem corresponder a dímeros de SMases $\mathrm{D}$ ou outras moléculas com epítopos comuns.

Dados da literatura mostram que as classes de imunoglobulinas encontradas no soro de cavalo são comuns à maioria dos mamíferos, i.e., $\lg A, \lg E, \lg \mathrm{M}$ e $\lg \mathrm{G}$ (HELMS et al., 1970; ROCKEY et al., 1970) e, em eqüinos, a classe IgG possui várias subclasses denominadas de $\lg G a, \lg G b$, $\lg G c$ e $\lg G(T)$. Segundo $M C$ DOUGALL et al. (1975), as subclasses $\lg G a$ e $\lg G(T)$ são as predominantes e representam mais de $80 \%$ das subclasses de IgG no soro eqüino e que essas são as responsáveis pela neutralização de toxinas circulantes.

A partir dessas informações, analisamos a presença dessas subclasses de IgG nos soros eqüinos testes por ELISA de captura. Os resultados obtidos mostraram a presença das subclasses de $\lg G a$, IgGb, IgGc e $\lg G(T)$ nos soros testes e títulos mais elevados dessas subclasses no soro anti-SMases D, quando comparados ao anti-Aracnídico. Títulos elevados, principalmente de $\lg G a$ e $\lg G(T)$, têm sido associados à melhor capacidade neutralizante de soros produzidos contra venenos de serpentes (Bothrops sp e Crotalus sp) (FERNANDES et al., 1991 e 1997), escorpião (Tityus serrulatus) e aranhas (Loxosceles gaucho e Phoneutria nigriventri) (TORO et al., 2006).

Após a caracterização dos soros, foram realizados ensaios de neutralização das atividades tóxicas induzidas pelos venenos de Loxosceles em modelos in vivo e in vitro. 
Uma das atividades tóxicas dos Loxosceles é a dermonecrose que pode ser induzida em modelos experimentais como coelhos e cobaios (ATKINS et al., 1958; MORGAN et al., 1969). Tal atividade foi determinada para as partidas de venenos utilizadas, pela inoculação de $3 \mu \mathrm{g}$ das peçonhas de Loxosceles (Dose Mínima Necrosante para a de L. gaucho - DMN - estabelecida pelo Setor de Controle de Qualidade do Instituto Butantan), no dorso de coelhos adultos e as lesões acompanhadas durante 72 horas. Nessa análise foi mostrado que as partidas dos venenos de L. gaucho, L. intermedia e L. laeta coletadas foram capazes de induzir dermonecrose, sendo que o de L. intermedia apresentou menor capacidade de induzir lesão do que os venenos de L. laeta e L. gaucho. Essas observações estão de acordo com os dados de Oliveira et al. (2005) que mostraram diferenças na toxicidade local e sistêmica induzidas pelos venenos de L. intermedia e L. laeta.

Com base na técnica desenvolvida por Furlanetto et al. (1961) e usada pelo Setor de Controle de Qualidade do Instituto Butantan, para determinação da capacidade neutralizante do soro anti-Aracnídico, realizamos 0 ensaio de neutralização "in vivo" da atividade dermonecrótica, com pequenas modificações. 0 método original consiste na inoculação de $3 \mu \mathrm{g}$ do veneno de Loxosceles gaucho, pela via intradérmica, em uma das orelhas de coelhos adultos e da injeção concomitante, pela via endovenosa, de $1 \mathrm{~mL}$ do soro teste diluído 1:15, na outra orelha; a leitura da reação e, conseqüente, determinação da atividade neutralizante do soro, é realizada somente 24 horas pós-inoculação. Em nosso laboratório, o método foi modificado para inoculação dos venenos pela mesma via de administração, mas no dorso depilado dos coelhos, a fim de permitir uma mais precisa mensuração das lesões que foram realizadas ao longo de 72 horas para o melhor acompanhamento do processo de soroneutralização. Assim, foi observado que o soro anti-SMases $D$ foi mais eficiente na neutralização da ação 
dermonecrótica do veneno de $L$. laeta do que o anti-Aracnídico. Para o veneno de L. intermedia, o soro anti-SMases $D$ foi capaz de conter mais eficientemente o desenvolvimento da reação dermonecrótica nas primeiras 48 horas, sendo que, às 72 horas, percentuais semelhantes de neutralização foram determinados para os dois soros.

Apesar de ter sido possível perceber diferenças no potencial neutralizante dos antissoros por meio desta metodologia, para sua realização com sucesso é necessário profissional experiente na administração endoveneosa e implica em maior desconforto para o animal que recebe duas inoculações quase que concomitantemente.

Outra metodologia disponível para análise do potencial neutralizante de soros consiste na pré-incubação do veneno com diluições seriadas do soro teste e, posteriormente, após centrifugação para remoção dos imunocomplexos, na inoculação das misturas em animais. Tal metodologia foi utilizada por Bárbaro et al. (2005) para analisar o potencial neutralizante de soros anti-Loxoscélicos produzidos no Brasil. Os soros utilizados foram: o anti-Loxosceles produzido pelo Centro de Produção e Pesquisa de Imunobiológicos do Paraná (produzido contra os venenos de L. gaucho, L. intermedia e L. laeta) e o soro anti-Aracnídico (produzido pela imunização com o veneno de L. gaucho, Phoneutria nigriventri e Titys serrulatus), fabricado pela Divisão de Produção Bioindustrial do Instituto Butantan. Como resultados de soroneutralização esse trabalho mostrou que tais antivenenos eram capazes de neutralizar a atividade dermonecrótica em $100 \%$ dos venenos de $L$. gaucho, L. intermedia, L. laeta e L. reclusa.

Usando tal metodologia e analisando os resultados 72 horas após a inoculação, para uma melhor determinação da atividade residual do veneno, verificamos que o soro anti-SMases $D$ teve maior capacidade de neutralização do 
que o anti-Aracnídico para os venenos de L. intermedia e L. laeta, sendo que para esse último o soro anti-SMases D foi capaz de inibir em 100\%, em todas as diluições testadas. Entretanto, para o veneno de L. gaucho os dois soros apresentaram potencial neutralizante similar até a diluição de 1:75, sendo na de 1:90 e 1:120, o soro anti-Aracnídico se mostrou mais eficiente. Esses dados complementam os dados obtidos nos ensaios in vivo de soroneutralização da atividade dermonecrótica, mostrando a o melhor reconhecimento do soro anti-SMases $D$ para os venenos de L. intermedia e L. laeta.

A hemólise e as alterações na superfície celular foram utilizadas como parâmetro para medir o potencial neutralizante dos soros frente ao efeito sistêmico dos venenos de Loxosceles. Eritrócitos humanos foram incubados com concentrações crescentes dos venenos e em seguida incubados com soro humano autólogo, como fonte de proteínas da cascata do sistema do complemento. Os resultados obtidos mostram que os três venenos de Loxosceles foram capazes de induzir hemólise dependente de complemento e a dose de $3 \mu \mathrm{g}$ eleita para os ensaios de soroneutralização, pois esta induziu percentuais de lise entre 70 e 100 .

Tambourgi et al. (2000 e 2002) mostraram que os venenos de Loxosceles transformam as hemácias humanas em células ativadoras das vias alternativa e clássica do sistema do complemento autólogo após a ligação das SMases D às suas superfícies celulares. A falha da regulação deste sistema deve-se à remoção das porções ricas em ácido siálico das glicoforinas e perda de assimetria de membrana (TAMBOURGI et al., 2000; 2002; 2007). Assim, o mecanismo proposto pelos autores para explicação da hemólise intravascular que ocorre nos casos de envenenamento sistêmico, envolve a clivagem de esfingomielina, presente na superfície dos eritrócitos, por ação esfingomielinásica das isoformas ativas dos venenos, seguida da ativação de uma protease de membrana que teria a capacidade de clivar as 
porções extracelulares das glicoforinas, o que permite a ativação da via alternativa do complemento com conseqüente hemólise. Os dados obtidos por estes autores ainda ressaltam a importância das glicoforinas, principalmente GPC, na manutenção da regulação da ativação de complemento autólogo. Por outro lado, a ligação das SMases à superfície das hemácias e clivagem do substrato induz perda de assimetria da membrana, com exposição de fosfatidilserina na face externa, o que permite a ativação da via clássica do Complemento.

Com base nesses achados e impossibilitados tecnicamente de medir o potencial neutralizante dos soros em ensaios hemolíticos, uma vez que a presença de anticorpos e ou imunocomplexos na reação poderia levar: 1) ativação do Complemento em fase fluida e, conseqüente, consumo ou lise reativa, 2) a ativação do Complemento na superfície dos eritrócitos e, conseqüente hemólise, por interação de $\mathrm{C} 1$ aos anticorpos dos soros teste que interagiram com as SMases D ligadas membranas. Qualquer um desses eventos geraria falsos resultados, e por isso foram utilizados como parâmetros para avaliar o potencial neutralizante dos soros sobre a atividade indutora de hemólise dos venenos, as análises de remoção de GPC e a ligação das SMases às membranas dos eritrócitos.

Nestes ensaios amostras de venenos foram incubadas junto com as diluições crescentes dos soros-teste foram adicionadas aos eritrócitos humanos. Como controle, foram testadas também amostras de veneno incubadas com soro eqüino não relacionado aos venenos de Loxosceles, ou seja, o anti-Botrópico. Após esse período, as células foram extensivamente lavadas e marcadas com anticorpo monoclonal dirigido contra a porção extracelular da GPC (BRIC 4) e a fluorescência determinada por citometria de fluxo.

Os resultados obtidos revelaram que o soro anti-Botrópico não teve a capacidade de inibir a remoção de GPC da membrana dos eritrócitos tratados com 
os venenos de Loxosceles, o que já era esperado, tendo em vista que este não é um soro específico para estas peçonhas. Para os soros testes os resultados mostraram que o soro anti-SMases $D$ teve maior capacidade de inibir a remoção de GPC da membrana de eritrócitos tratados com o veneno de L. laeta e $L$. intermedia, quando comparado ao soro anti-Aracnídico. No entanto, para o veneno de L. gaucho, o soro anti-SMases D não inibiu com eficiência a remoção de GPC.

Essas observações podem ser em parte correlacionadas com os resultados da inibição da ligação das SMases $D$ à membrana dos eritrócitos, pelos quais foi verificado que o soro anti-SMases $D$ teve maior capacidade de inibir a ligação dessas enzimas do que o anti-Aracnídico. Esse fato é importante, uma vez que a ligação de SMases $D$ à membrana de células é um dos eventos principais para o desenvolvimento do loxoscelismo. Entretanto, apesar do soro anti-SMases D ter a capacidade de inibir esse evento para os três venenos estudados, quantidades residuais de SMase $D$ ligadas às membranas, mas não detectáveis pelos métodos aqui utilizados, podem ser as responsáveis pela remoção de GPC detectada nas células tratadas com amostras do veneno de L. gaucho pré-incubadas como soro anti-SMases D.

Alternativamente, pode-se supor que as SMases D de L. intermedia e L. laeta possam eficazmente induzir anticorpos contra as porções responsáveis pela ligação destas toxinas, das três espécies de Loxosceles, mas menos eficientemente contra o sítio ativo. Tal fato resultaria no impedimento da ligação das SMases D presentes no veneno de L. gaucho às membranas, mas parte delas, não totalmente neutralizadas e em fase solúvel, seriam ainda capazes de hidrolisar esfingomielina de membrana, ativar as proteases endógenas e causar a remoção de GPC observada nas células tratadas com veneno de L. gaucho pré-incubado com soro anti-SMases D nas diluições de 1:150, 1:750 e 1:1500. 
A atividade esfingomielinásica é responsável pelo efeito dermonecrótico e hemolítico dependente de sistema do complemento dos venenos de Loxosceles (FORRESTER et al., 1998; KURPIEWSKI et al., 1981; TAMBOURGI et al., 1998, TAMBOURGl et al., 2000; FERNANDES-PEDROSA et al., 2002; TAMBOURGI et al, 2004; TAMBOURGl et al, 2005, 2007).

A análise de atividade esfingomielinásica, presente nos venenos das três espécies de Loxosceles, revelou que todos são capazes de hidrolisar esfingomielina de forma dose-dependente, sendo que o de $L$. gaucho foi o mais ativo, uma vez que concentrações de $150 \mathrm{ng}$ desse produziram hidrólise significativa do substrato, fato não observado para outros venenos. Por outro lado, amostras de $1 \mu \mathrm{g}$ das três peçonhas produziram valores semelhantes de hidrólise da esfingomielina, o que nos levou a definir esta dose como aquela a ser utilizada nos ensaios de soroneutralização desta atividade.

Assim, amostras de $1 \mu \mathrm{g}$ dos venenos foram incubadas com os soros-teste, nas mesmas diluições utilizadas no ensaio de neutralização da atividade dermonecrótica in vitro-in vivo. As amostras dos sobrenadantes das reações foram incubadas com o substrato esfingomielina, para determinação da atividade residual das SMases $D$ presentes nos venenos. Os resultados obtidos revelaram que, embora o soro anti-Aracnídico tenha sido mais eficiente do que o anti-SMases D em neutralizar a atividade esfingomielinásica do veneno de L. gaucho até a diluição de 1:60 e de $L$. intermedia e $L$. laeta até 1:15, nas demais diluições, a atividade neutralizante foi similar ou superior para o soro anti-SMases D.

Olvera et al., 2006 mostraram que o soro produzido contra SMases D recombinantes de $L$. laeta, $L$. reclusa e $L$. boneti, quando utilizado na diluição de 1:2, foi capaz de neutralisar a atividade esfingomielinásica presente nos venenos de $L$. laeta, L. reclusa e L. boneti. 
Analisando-se comparativamente os resultados obtidos nos ensaios de soroneutralização das atividades dermonecrótica (in vitro-in vivo) e esfingomielinásica, que utilizaram as mesmas diluições dos soros, observa-se que apesar de haver neutralização total e/ou parcial da dermonecrose pelos soros, foi ainda detectada uma significante atividade esfingomielinásica residual nos venenos, ressaltando a importância de métodos com maior sensibilidade para determinação da capacidade neutralizante dos soros. Assim, o método fluorimétrico aqui padronizado, para medição do potencial neutralizante de soros antivenenos de Loxosceles, é uma alternativa rápida, reprodutível, de alta sensibilidade, que abole o uso de animais de experimentação e que poderá ser usada para o controle de qualidade em substituição ao, atualmente, utilizado que é o da soroneutralização da atividade dermonecrótica em ensaios in vivo.

Com base nos resultados obtidos podemos concluir que o soro anti-SMases D foi mais eficiente na neutralização das atividades dermonecrótica, esfingomielinásica, de indução da remoção de GPC e da ligação das SMases D à membrana de eritrócitos humanos, dos venenos de L. intermedia e L. laeta, do que o anti-Aracnídico. Entretanto, para o veneno de L. gaucho o soro anti-SMases D apresentou neutralização similar ou menor para as atividades tóxicas do que o antiAracnídico. Tais dados, portanto, sugerem que para melhorar o potencial neutralizante do soro anti-SMases $D$ frente a todos os venenos de Loxosceles com importância médica no Brasil para ser utilizado na terapia humana, toxinas do veneno de L. gaucho devem ser incluídas na mistura de imunização dos cavalos. 


\section{REFERÊNCIAS BIBLIOGRÁFICAS}

AMNS, H.H.; DUNNICK, C.A.; SMITH, M.L.; KING Jr.; L.E. Necrotic arachnidism. J. Am. Acad. Dermatol., v.44, p. 561-573, 2001.

ANDERSON, P.C. Necrotizing spider bites. Ann. Fam. Physician., v. 26, p.198-203, 1982.

ANDRADE, R.M.G.; OLIVEIRA, K.C.; GIUSTI, A.L.; SILVA, W.D.; TAMBOURGI, D.V. Ontogenetic development of Loxosceles intermedia spider venom. Toxicon, v. 37, p. 627-632, 1998.

ANDRADE, A.S.; MURAKAMI MT.; CAVALCANTE D.P.; ARNI RK.; TAMBOURGI D.V. Kinetic and mechanistic characterization of the Sphingomyelinases $D$ from Loxosceles intermedia spider venom. Toxicon, v. 47, p.380-6, 2006.

ATKINS, J. A.; WINGO, C.W.; SODEMAN, W.A.; FLYNN, J. E. Necrotic arachnidism. Am. J. Trop. Med., v. 7, p.165-184, 1958.

BALDWIN, G.A.; SMITH, D.F.; FIKE, S.D. Loxoscelism in Canada. Can. Med. Assoc. J., v. 138, p. 521-522, 1988.

BÁRBARO, K.C.; CARDOSO J.L.; EICKSTEDT, R.; MOTTA I. Dermonecrotic and letal components of Loxosceles spider venom. Toxicon, v.3, p.331-8, 1992.

BÁRBARO, K.C.; CARDOSO, J.L. Mecanismo de ação do veneno de Loxosceles e aspectos clínicos do Loxoscelismo. In: CARDOSO, J.L.C.; FRANÇA, F.OS., FAN, H.W., MÁLAQUE C.M.S. HADDAD, Jr. V (Ed.) Animais peçonhentos no Brasil Biologia, clínica e Terapêutica dos Animais. São Paulo: Sarvier, 2003, p.160-174.

BÁRBARO K.C.; EICKSTEDT V.R.D.; MOTTA I. Antigenic cross-reactivity of venoms from medicall important Loxosceles (Araneae) species in Brazil. Toxicon, v.32. p.113-120, 1994.

BÁRBARO, K.C.; SOU, M.V.; MORHY, L.; EICKSTEDT, V.R.; MOTA, I. Compared chemical properties of dermonecrotic and lethal toxins from spiders of genus Loxosceles (Araneae). J. Protein Chem., v.15, p. 337-343, 1996.

BÁRBARO, K.C; KNYSAK, I.; MARTINS R.; HOGAN, C.; WINKEL, K. Enzymatic characterization, antigenic cross-reactivity and neutralization of dermonecrotic activity of five Loxosceles spider venoms of medical importance in the Americas. Toxicon, v.45, p-489-499, 2005. 
BEY, T.A.; WALTER, F.G.; LOBER, W.; SCHIMIDT, J.; SPARK, R.; SCHLIEVERT, P.M. Loxosceles arizonica bite with shock. Ann. Emerg. Med., v. 30, p. 701-703, 1997.

BRAUCH, H.; ROELCKE, D.; ROTHE, U. Glycophorin A inhibits lysis by attack phase. Immunobiol., v.165, p.115-120, 1983.

BRAZ, A.; MINOZZO, J.; ABREU, C.J.; GUBERT, I.C.; OLORTEGUI-CHAVÉ, C. Development and evaluation of the neutralizing capacity of horse antivenom against the Brazilian spider Loxosceles intermedia. Toxicon, v. 37, p. 1323-1328, 1999.

BRAZIL V. Contribution à L'étude d'origine ophidiene. A. Maloine,1905.

BUCHERL, W. Biology and venoms of the most important South American spider of genera Phoneutria, Loxosceles, Lycosa and Latrodectus. Am. Zool., v.9, p.157-159, 1969.

BUTZ, W.C.; STACY, L.D.; HERYFORD, N.N. Arachnidism in rabbits. Arch. Pathol., v.91, p.97-100, 1971.

CADERNOS DE SAÚDE DE CURITIBA. Loxosceles: "A aranha marrom". Local: Curitiba, 1993, 2, 10p.

CARDOSO,J.L.C.; FRANÇA, F.O.S; VON EICKSTEDT, V.R.D; BORGES, I.; NOGUEIRA, M.T. Loxoscelismo: estudo de 242 casos (1980). Rev. Soc. Bras. Toxicol. v.1, 58-60, 1988.

CAVENESS, W. Insect bite complicated by fever. Nashville J. Méd. Surg., v. 10, p.333, 1872.

CALMETTE, A. Contribuition à l'étude du venin dês serpentes. Immunisation dês animax et traitament de l'evenimation. Ann. Inst. Pasteur, v. 8, 275-91, 1894.

DA SILVA, P.H.; DA SILVEIRA, R.B.; APPEL, M.H.; MANGILI, O.C.; GREMSKI, W.; VEIGA, S.S. Brown spiders and Loxoscelism. Toxicon, v. 44, p. 693-709, 2003.

DE ANDRADE A.S.; PEDROSA M.F.; DE ANDRADE R.M.; OLIVA M.L.; van den BERG C.V.; TAMBOURGI D.V. Conformational changes of Loxosceles venom 
sphingomyelinases monitored by circular dichroism. Biochem. Biophys. Res. Commun., v. 327, p.117-123, 2005.

DE ROODT, A.R.; ESTEVEZ-RAMÍREZ, J.; LITWIN, S.; MAGAÑA, P.; OLVERA, A.; ALAGÓN, A. Toxicity of two North American Loxosceles (brown recluse spiders) venoms and their neutralization by antivenoms. Clin. Toxicol. v.45, p.678-687, 2007.

DE OLIVEIRA, K.C.; ANDRADE, R.M.G.; GIUSTI, A.L.; SILVA, W.D.; TAMBOURGI, D.V. Sex-linked variation of Loxosceles intermedia spider venoms. Toxicon, v. 37, p. 217-221, 1999.

DE OLIVEIRA K.C.; ANDRADE, R.M.G.; PIAZZA R.M.; FERREIRA J.M. Jr.; van den Berg C.W.; TAMBOURGI D.V. Variation in Loxosceles spider venom composition and toxicity contribute to the severity envenomation. Toxicon, v. 45, p. 421-9, 2005.

DESAI, A.; LANKFORD, H.A.; WARREN J.S. Loxosceles deserta spider venom induces the expression of vascular endothelial growth factor (VEGF) in keratinocytes. Inflammation, v. 24, p-1-9, 2000.

FERNANDES-PEDROSA, M.; JUNQUEIRA DE AZEVEDO, I.; GONÇALVES-DEANDRADE, R.M.; van den BERG, W.C.; RAMOS, C.R.; HO, P.L.; TAMBOURGI, D.V. Molecular cloning and expression of a functional dermonecrotic and haemolytic factor from Loxosceles laeta venom. Biochem. Biophys. Res. Comm., v. 298, p.638-45. 2002.

FERNANDES, I; MOTA I. Isolation of IgGT from hiperimmune horse anti-snake venom serum: its protective ability. Toxicon, v.29, p.1373-1379, 1991.

FERNANDES, I; TAKEHARA, H.A; SANTOS A.C.; CORMONT, F.; LATINNE, D.; BAZIN, H. MOTA, I. Neutralization of bothropic and crotalic venom toxic activities by $\lg \mathrm{G}(\mathrm{T})$ and $\mathrm{lg} \mathrm{Ga}$ subclasses isolated from the immune horse serum. Toxicon, v.35, p.931-6, 1997.

FEARON, D. Regulation by membrane sialic acid $\beta 1 \mathrm{H}$ dissociation of amplification C3 convertase of the alternative C pathway. Proc Natl. Acad. Sci., v.75, p.19711975, 1978.

FISCHER, M.L. Levantamento das Espécies do gênero Loxosceles. HEINECKEN E LOWE, 1832 no Município de Curitiba, Paraná, Brasil. Estudos de Biologia, v.38, p.63-88, 1994. 
FORRESTER, J.T.; BARRET, L.J.; CAMPBELL, B.J. Red blood cell lysis induced by the venom of the Brown recluse spider. The role of sphingomyelinase D. Arch. Biochem. Biophys., v. 187, p. 355-365, 1978.

FUNDAÇÃO NACIONAL DE SAÚDE. Manual de DIAGNÓSTICO e TRATAMENTO de Acidentes por animais peçonhentos. Brasília, Ministério da Saúde, 49-61, 1998.

FURLANETTO, R.S. Estudos sobre a preparação do soro antiloxoscélico. Tese (livre docência). Universidade de São Paulo, São Paulo, 1961.

FUTRELL, J. Loxoscelism. Am. J. Med. Sci., v. 304, p. 261-267, 1992.

GOMEZ, H.F.; MILLER, M.J.; TRACHY, J.W.; MARKS, R.M.; WARREN, J.S. Intradermal anti-Loxosceles Fab fragments attenuate dermonecrotic arachnidism. Acad. Emerg. Med., v. 6, p. 1195-1202, 1999.

GONÇAVES DE ANDRADE, R.M.; DE OLIVEIRA, K.C.; GIUSTIA, A. L.; DIAS DA SILVA, W.; TAMBOURGI, D.V. Ontogenetic development of Loxosceles intermedia spider venom. Toxicon, v. 37, p.627, 1999.

GUILHERME, P.; FERNANDES, I.; BÁRBARO, C.K. Neutralization of dermonecrotic and lethal activities and differences among $32-35 \mathrm{kDa}$ toxins of medically important Loxosceles spiders venoms in Brazil revealed by monoclonal antibodies. Toxicon, v.39, p.1333-1342, 2001.

JONG, Y.S.; NORMENT, B.R.; HEITZ, J.R. Separation and characterization of venom components in Loxosceles reclusa. Protease enzyme activity. Toxicon, v.17, p. 529-537, 1979.

HELMS, C.M.; ALLEN, P.Z. Studies on equine immunoglobuline II. Antigenic interrelationships amons horse $\operatorname{lgG}$, IgGT and antipnemococcal 1 component. J. Immunol., v.91, p.11-17, 1963.

HOGAN, C.J.; BARBARO, K.C.; WINKEL, K. Loxoscelism: old obstacles new directions. Ann. Emerg.Med., v.44, p.608-624, 2004.

KINOSHITA, T. Biology of complement: the overture. Immunol. Today, v.12, p.291295, 1991.

KING, J.R. Brown recluse spiders bites: stay cool. Letter to the, editor. JAMA, v. 254, p. 2895-2896, 1985 
KURPIEWSKI, G.; FORRESTER, L.J.; BARRET, J.T.; CAMPBELL B.J. Platelet aggregation and sphingomyelinase $D$ activity of a purified toxin from the venom of Loxosceles reclusa. Bioch. Biophys. Acta., v.678, p. 467-476, 1981.

LUCIANO, M.N; DA SILVA, P.H.; CHAIM, O.M.; DOS SANTOS, V.L.; FRANCO C.R.; SOARES, M.F.; ZANATA, S.M.; MANGILI, ํ․; GREMSKI, W.; VEIGA, S.S. Experimental evidence for a directy cytotoxity of Loxosceles intermedia (brown spider) venom in renal tissue. J. Histochem. Cytochem., v.54, p.455-67, 2004.

MAY, J.E.; ROSSE, W.; FRANK, M.M. Paraxysmal noctunal hemaglobunuria. Alternative complement-pathway-mediated lysis induced by magnesium. N. Engl. J. Med., v.289, p.705-709, 1973.

MC DOUGALL, J.K. Adenoviruses - interaction with the host cell genome. Prog. Med. Virol., v.21, p118-132, 1975.

MACHIAVELLO, A. La Loxosceles laeta, causa del arachoidismo cutaneo, a mancha gangrenosa de Chile. Rev. Chil. Hist. Nat., v.41, p.11, 1947a.

MACHIAVELLO, A. Cutaneous arachnisdism or gangrenous spot of Chile. Pub. Health Trop. Med., v.22, p.425, 1957b.

MALAQUE, C.M.; ORI, M.; SANTOS, A.S.; ANDRADE, D.R. Production of TNF- $\alpha$ by primary cultures of human keratinocytes challenged with Loxosceles gaucho venom. Rev. Inst. Med. Trop. S. Paulo, v.41, p. 179-182,1999.

MANUAL DE DIAGNÓSTICO E TRATAMENTOS DE ACIDENTES POR ANIMAIS PEÇONHENTOS. Brasília: Ministério da Saúde, 1998.

MEETEREN, VAN LA.; FREDERICKS, F.; GIEPMANS, B.N.; PEDROSA, M.F.; BILLINGTON, S.J.; JOST, B.H; TAMBOURGI, D.V.; MOOLENAR, W.H. Spider and bacterial sphingomyelinases $\mathrm{D}$ target cellular lysophosphatidic acid receptors by hydrolyzing lysophosphatidylcholine. J. Bio. Chem., v.279, p. 10833-6, 2004.

MORGAN, P. N. Preliminary studies on venom from the brown recluse spider Loxosceles reclusa. Toxicon, v.6, p. 161-165, 1969.

MURAKAMI, M.T.; FERNANDES PEDROSA, M.F.; TAMBOURGI, D.V.; ARNI, R.K. Structural basis for metal ion coordination and the catalytic mechanism of sphingomyelinases. J. Biol. Chem., v.280, p.138-164. 2005. 
NEWLANDS, G.; ISAACSON, C.; MARTINDALE. Loxoscelism in the Transvaal, South Africa. Trans. R. Soc. Trop. Med. Hyg., v.76, p.610-615, 1982.

NORMENT, B.R.; JONG, Y-S.; HEITZ, J.R. Separation and characterization of venom components in Loxosceles reclusa - III. Hydrolytic enzyme activity. Toxicon, v. 17 , p. $539-548,1979$.

OLVERA, A.; RAMOS-CERILLO, B.; ESTEVEZ, J.; CLEMENT, H.; DE ROODT, A.; PANIAGUA-SÓLIS, J.; VÁZQUEZ, H.; ZAVALETA, A.; ARRUZ, M.S.; STOCK, R.P.; ALAGÓN, A. North and South American Loxosceles spiders: development of a polyvalent antivenom with recombinant sphingomyelinases $D$ as antigens. Toxicon, 48, p. 64-74, 2006.

OKADA, N.; YASUDA, T.; TSUMITA, T.; SHINOMIYA, H.; UTSUMI, S.; OKADA, H. Regulation by glycophorin of $\mathrm{C}$ activation via the alternative pathway. Biochem. Biophys. Res. Commun., v. 108, p.770-775, 1982.

PAIXÃO-CAVALCANTE, D.; van den BERG, C.V.; GONÇALVES DE ANDRADE, R.M.; FERNANDES-PEDROSA, M.F.; OKAMOTO, C.K.; TAMBOURGI, D.V. Tetracycline protects against dermonecrosis induced by Loxosceles spider venom. J. Invest. Dermatol., v.127, p.1410-1418, 2007.

PAIXÃO-CAVALCANTE, D.; van den BERG, C.V.; FERNANDES PEDROSA, M.F.; GONÇALVEZ DE ANDRADE, R.M.; TAMBOURGI, D.V.; Role of matrix metalloproteinases in HaCat keratinocytes apoptosis induced by Loxosceles venom shpngomyelinase D. J. Invest. Dermatol., v. 126, p.61-68, 2006.

PANGBURN, M.K.; MULLER-EBERHARD, H.J. Complement C3 convertase: cell surface restriction of $\beta 1 \mathrm{H}$ control and generation of restriction on neuraminidasetreatred cells. Proc Natl. Acad. Sci. USA, v.75, p.2416-2420, 1978.

PATEL, K.D.; MODUR, V.; ZIMMERMAN, G.A.; PRESCOTT, S.M.; MCINTRYRE, T.M. The necrotic venom of the brown recluse spider induces dysregulated endothelial cell-depedent neutrophil activation - differential induction of GM-CSF, IL8 and E-selectin Expression. J. Clin. Invest., v.94, p.631-642, 1994.

PAULI, I.; PUKA, J.; GUBERT, C.I.; MINOZZO, J.C. The efficacy of antivenom in loxoscelism treatment. Toxicon, v. 48, p.123-137, 2006.

PLATNICK, N, I. The world spiders catalog, version 5.5. American Museum of natural history, site: http://reserarch.amnh.org/entomology/spiders/catalog/index.htmal, 2005. 
PRETEL, F.; GONÇALVES DE ANDRADE, R.M.; MAGNOLI, F.C.; DA SILVA, M.E.; FERREIRA, J.M; van den BERG, C.W.; TAMBOURGI, D.V. Analysis of the toxic potential of venom from Loxosceles adelaida, a Brazilian brown spider from karstic areas. Toxicon, v.45, p.449-58, 2005.

REES, R. S.; NANNEY, L.B.; YATES, R.A.; KING L.E. J.R. Interaction of brown recluse spider venom on cell membranes: the inciting mechanism? J. invest. Dermatol., v.83, p.270-275, 1981.

REES, R.S.; ALTERMBERN, D.P.; LYNCH, J.B.; KING, J.R. L.E. Brown recluse spider bites: a comparison of early surgical excision versus dapsone and delayed surgical excision. Ann. Surg., v. 83 , p. 659-663, 1985.

RUSSEL, F.E. Injuries by venomous animals in United States. JAMA, p.177- 903, 1961.

ROCKEY, S.M.; KLINMAN, N.R.; KARUSH, F. Equine immunoglobulins I - Studies on the antigenic struture of horse lgG, it's fragments ans subunits. Immunochemistry, v.7, p.401-412, 1970.

ROSSE, W.F. Phosphatidylinositol-like proteins and paroxysmal nocturnal hemaglonuriria. Blood, v.75, p. 1595-1601, 1990

SCHENONE, F.H. Cuadros tóxicos producidos por mordeduras de araña en Chile: latrodectismo y loxoscelismo. Rev. Med. Chile, v.131, p. 437-444, 2003.

SCHMAUS, L.F. Case arachnidism (spider bite). JAMA, v.92, p.1265-1266, 1929.

SEZERINO, U.M.; ZANNIN, M.; COELHO, L.K.; GONÇALVES, Jr.; GRANDO, M.; MATTOSINHO, S.G.; CARDOSO, J.L.C.; EICKSTEDT, V.D.R.; FRANÇA, F.O.S.; BÁRBARO, K.C.; FAN, H. W. A clinical and epidemiological study of Loxosceles spider envenoming in Santa Catarina, Brazil. Trans. R. Soc. Trop. Med. Hyg., v.92, p.546-548, 1998.

SHIP, A.G. Loxoscelism. Letter to the editor. N. Engl. J. Med., v.339, p.1945, 1998.

SILVA, P.H.; HASHIMOTO, Y.; SANTOS, F.A.; MANGILI, C.O. Hematological cell findings in bone morrow and peripheral blood of rabbits after experimental acute expose to Loxosceles intermedia (Brown spider) venom. Toxicon, v. 42, p.155-161, 2003. 
SMITH, C. W.; MICKS, D. W. The role of poymorphonuclear leukocytes in the venom of the browm recluse spiders, Loxosceles reclusa. Lab. Invest., v.22, p.90-90, 1970.

TAMBOURGI, D.V.; MAGNOLI, F.C.; von EICKSTEDT, V.R.; BENEDETTI, Z.C.; PETRICEVICH, V.L.; DIAS DA SILVA, W. Incorporation of a 35-kilodalton purified protein from Loxosceles intermedia spider venom transforms human erythrocytes into activators of autologous complement alternative pathway. J. Immunol., v. 155, p. 4459-4466, 1995.

TAMBOURGI, D.V.; PETRICEVICH, V.L.; MAGNOLI, F.C.; ASSAF, S.L.; JANCAR, S.; DIAS DA SILVA, W. Endotoxemic-like shock induced by Loxosceles spider venoms, pathological changes and putative cytokine mediators. Toxicon, v.3, p. 391403, 1998.

TAMBOURGI, D.V.; MORGAN, B.P.; GONÇALVES DE ANDRADE, R.M.; MAGNOLli, F.; van den BERG. C.W. Loxosceles intermedia spider envenomation induces activation of an endogenous metalloproteinase, resulting in cleavage of glycophorins from the erythrocyte surface and facilitating complement-mediated lysis.

Blood, v. 95, p.683-691, 2000.

TAMBOURGI, D.V.; DE SOUSA DA SILVA, M.; BILLINGTON, SJ., GONÇALVES DE ANDRADE, R.M; MAGNOLI, F.C.; SONGER, J.C.; van den BERG, C.W. Mechanism of induction of complement susceptibility of erythrocytes by spider and bacterial sphingomyelinases. Immunology, v. 107, p. 93-101, 2002

TAMBOURGI, D.V.; PEDROSA, M.F.; van den BERG, C.W.; ANDRADE, R.M.G.; FERRACINE, M.; PAIXÃO-CAVALCANTE, D.; MORGAN, B. P.; RUSHMERE, N.K. Molecular cloning, expression, function and immunoreactivities of members of a gene family of sphingomyelinases from Loxosceles venom glands. Mol. Immunol., v.41, p.831-840, 2004.

TAMBOURGI, D.V.; CAVALCANTE, D.P.; DE ANDRADE, R.M.G.; FERNANDESPEDROSA, F.M.; MAGNOLI, F.; MORGAN, P.B.; van den BERG, W.C . Loxosceles sphingomyelinase induces complement-dependent dermonecrosis, neutrophils infiltration, and endogenous gelatinase expression. J. Invest. Dermatol., v.214, p.725-731, 2005.

TAMBOURGI, D.V.; PEDROSA, M.F.; DE ANDRADE, R.M.; BILLINGTON, S.J.; GRIFFITS, M.; van den BERG, W.C.; Sphingomyelinases D induce direct association of $\mathrm{C} 1 \mathrm{q}$ to the erythrocyte membrane causing complement mediated autologous haemolysis. Mol. Immunol.,v. 44, p.576-82, 2007. 
TANNER, M.J.A. The major integral proteins of the human red cell. Baillière Clin Haematol., v.6, p.333-356, 1993.

TAVARES, F.L.; SOUZA E SILVA, M.C.; SANTORO, M.L.; BÁRBARO, K.C.; REBECCHI, I.M.; SANO-MARTINS, I.S. Changes in hematological, hemostatic and biochemical parameters induced experimentally in rabbits by Loxosceles gaucho spidervenom. Hum. Exp. Toxicol., v. 23, p. 477-86, 2004.

TOKOMURA, A; MAJIMA E.; KARIYA, Y.; TOMINAGUA, K.; KOGUNE, K.; YASUDA, K.; FUKUZAWA, K. Increased production of bioactive lysophosphatidic acid by serum lysophospholipase D in human pregnancy. J. Biol. Chem., v. 277, p. 39436-39442, 2002.

TORO, A.F.; MALTA, M.B.; SOARES, S.L.; DA ROCHA, G.C.; DA SILVA, LIRA M.; DE OLIVEIRA, T.A; TAKEHARA, H.A; LOPES-FERREIRA, M; SANTORO, M.L; GUINDOLIN, R.; GONDO HIGASHI, I.; FERNANDES, I.; BÁRBARO, K.C. Role of $\lg \mathrm{G}(\mathrm{T})$ and $\operatorname{lgGa}$ isotypes obtained from arachnidic antivenom to neutralize toxic activities of Loxosceles gaucho, Phoneutria nigriventer and Tityus serrulatus venoms. Toxicon, v. 48, p.649-61, 2006.

van den BERG, C.W.; DE ANDRADE, R.M.; MAGNOLI, F.; MARCHBANK, K.; TAMBOURGI, D.V. Loxosceles spider venom induces metalloproteinase-mediated cleavage of $\mathrm{MCP} / \mathrm{CD} 46$ and $\mathrm{MHCl}$ and induces protection against $\mathrm{C}$-mediated lysis. Immunology, v.107, p.102-110, 2002.

van den BERG, C.W.; GONÇALVES DE ANDRADE, RM; MAGNOLI, F.C.; TAMBOURGI, D.V. Loxosceles spider venom induces the release of thrombomodulin and endothelial protein $C$ receptor: implications for the pathogenesis of intravascular coagulation as observed in loxoscelism. J. Thromb. Haem., v.5, p. 989-95, 2007.

VEIGA, S.S.; DA SILVEIRA, R.B.; DREYFUSS, J.L.; HAOACH, J.; PEREIRA, A.M.; MANGILI, O.C.; GREMSKI, W. Identification of hight molecular weight serineproteases in Loxosceles intermedia (Brown spider) venom. Toxicon, v. 38, p.825839, 2000.

VEIGA, S.S.; ZANETTI, V.C.; FRANCO, C.R.C.; TRINDADE, E.S; PORCIONATTO, M.A.; MANGILI, O.C.; GREMSKI, W.; DIETRICH, C.P.; NADER, H.B. In vivo and In vitro cytotoxicity of brown spider venom for blood vessel endothelial cells. Thromb. Res., v.102, p. 229-237, 2001a.

VEIGA, S.S.; ZANETTI, V.C.; BRAZ, A.; MANGILI, O.C.; GREMSKI, W. Extracellular matrix molecules as targets for Brown spider venom toxins. Braz. J. Med. Biol. Res., v. 34, p. $843-850,2001 b$. 
WASSERMAN, G.S.; ANDERSON, P.C. Loxoscelism and necrotic arachnidism. J. Toxicol. Clin., v. 21, p. 451-72, 1983.

WENDELL, R.P. Brown recluse spiders: a review to help guide physicians in noendemic áreas. South Med. J., v.96, p. 486-490, 2003.

WHITE, J.; CARDOSO, J.L.; FAN, H.W. Clinical toxicology of spider bites. Handbook of clinical toxicology of animal venoms and Poison, CRC. Local: Boca Raton, 1995, p.261-329.

WRIGHT, R.P.; ELGERT, K.; CAMPBEL, B.J.; BARRET, J.T. Hyaluronidase and esterase activities of the venom of the poisonous Brown recluse spider. Arch. Biochem. Biophys., v. 159, p 415-426, 1973.

YONG, A. R.; PINCUS, S.J. Comparasion of enzymatic activity from three species of necrotising arachnids in Australia: Loxosceles refuscens, Badumma insignis and Llampona cylindrata. Toxicon, v.39, p.391-400, 2001. 